\title{
Biopathology of astrocytes in human traumatic and complicated brain injuries. Review and hypothesis
}

\author{
Orlando José Castejón \\ Biological Research Institute, Faculty of Medicine, Zulia University, Maracaibo, Venezuela
}

\begin{abstract}
The biopathology of astrocyte cells in severe human brain traumatic injuries complicated with subdural and epidural haematoma and hygroma is reviewed. Clear and dense oedematous and hypertrophic reactive astrocytes are distinguished in severe primary traumatic vasogenic and secondary cytotoxic brain oedema. Swollen perineuronal astrocytes appear compressing and indenting clear and dark degenerated pyramidal and non-pyramidal nerve cells, degenerated myelinated axons and synaptic contacts. Hypertrophic astrocytes display dense cytoplasm and contain numerous rosettes of alpha, beta- and gamma-type glycogen granules, swollen mitochondria, dilated smooth and rough endoplasmic reticulum, oedematous Golgi apparatus, microtubules, gliofilaments, intermediate filaments, lysosomes and liposomes. The perisynaptic astrocyte ensheathment of synaptic contacts, containing beta type-glycogen granules, can be traced in the neuropil, surrounding swollen, bead-shaped dendritic profiles, and degenerated myelinated axons. This perisynaptic glial layer is absent in severe oedematous regions. The glycogen-rich and glycogendepleted perivascular astrocyte end-feet appear attached or dissociated from the capillary basement membrane. Phagocytic astrocytes can be seen engulfing degenerated synaptic contacts, necrotic membranes, degenerated myelinated axons, and myelin ovoids. Lipofuscin-rich astrocytes are also observed. The interastrocytary gap junctions appear either widened, fused or fragmented.

The key role of aquaporin in astrocyte swelling and brain oedema is emphasized. The findings are compared with those reported in experimental traumatic animal models, a large variety of pathogenetically related neuropathological conditions, and in vivo and in vitro experimental conditions. The contribution of pathological astrocytes to neurobehavioral disorders, such as loss of consciousness, neurological deficits and seizures is emphasized. Some hypotheses are postulated related to the dissociated or absent perisynaptic layer, neurobiology of glycogen-rich and glycogen-depleted perivascular astrocytes, the glio-basal dissociation process, abnormal astrocyte-neuronal unit, and astrocyte participation in seizures in patients with severe and complicated brain injuries.
\end{abstract}

Key words: astrocytes, brain trauma, brain oedema, light microscopy, electron microscopy.

\section{Introduction}

\section{Astrocyte changes in traumatic brain injuries}

Astrocyte reactions to traumatic brain injuries have been the topic of many studies and of much debate for almost a century. The current consent is that glial cells, mainly astrocyte cells, have a pivotal role in degeneration and regeneration of the gray matter, and that astrocyte changes are one of the hallmarks of the response of the central nervous system (CNS) to injury $[1,8,12,15,17,44,58,65,68-70,74$, $76,81,86,88,94-96,98,99,102,109,129,138]$. The astrocyte cell changes in brain injuries have been widely

Communicating author:

Prof. Orlando José Castejón, MD, Biological Research Institute, Faculty of Medicine, Zulia University, Maracaibo, Venezuela, fax: 58-261-7831611, e-mail: ocastejo@cantv.net 
studied at light and electron microscope levels. Such earlier studies in human and experimental animals reported a wide spectrum of pathological changes, such as astrocyte swelling, division and proliferation (gliosis), gemistocytic astrocytes, a type of round to oval hypertrophic astrocyte cell with abundant cytoplasm containing glial filaments and an eccentric nucleus or two nuclei, clasmatodendrosis or astrocytes with breaking up of astrocytic protoplasmic expansions, active and reactive changes, accumulation of glial fibres and increased synthesis and expression of glial fibrillary acidic protein (GFAP), vimentin and glutamine synthetase, phagocytic properties, glycogen accumulation, intermediate filament gene expression, secretion of neurotrophic factors, migration, and down regulation of astrocyte glutamate transporter. An increased immunochemically detectable GFAP level was one of the earliest responses to specifically characterize CNS injuries [18, 21,51,52,54,60,65,68,77,81,125].

Castejón previously described astrocyte subtypes, morphological astrocytic changes and human neurobehavioral disorders in traumatic human oedematous cerebral cortex [27-32]. Ragaisis [120] found ischaemic swelling of astrocytes in brain contusion after increasing concentrations of potassium ion. Derugin et al. [45] and Fotheringham et al. [55] reported reactive astrocytes after transient middle cerebral artery occlusion. Del Bigio et al. [44] described astrocytic swelling and eosinophilia in human post-mortem brain indicative of plasma extravasation and brain oedema. According to Raivich et al. [119], damage to the CNS leads to cellular changes not only in the affected neurons but also in adjacent glial cells and endothelia, and frequently to recruitment of cells of the immune system. These cellular changes form a graded response which is a consistent feature in almost all forms of brain pathology. These authors provide evidence about the biological function of the neuroglial activation in the injured brain. Vajtr et al. [138] described in human cortical biopsies cytotoxic astrocyte oedema occurring during blood brain barrier damage after traumatic brain injury. According to Eng [52], GFA protein or GFAP is the major protein constituent of glial intermediate filaments in differentiated fibrous and protoplasmic astrocytes of the CNS. A putative function ascribed to glial filaments as a component of cytoskeletal substructures is defining and maintaining the shape of the astrocyte.
In the present review, I shall present the view supported by our light and electron microscopic laboratory data based on examinations of more than 60 human cortical biopsies immediately taken in the surgical room, and optimally fixed during the neurosurgical treatment. These studies have provided some insight into the subsets of astrocyte cells generated after severe and complicated traumatic brain injuries. A widely accepted view is that adult human CNS is inherently different from experimental animal models, and that astrocyte reactivity changes according to the aetiology or primary insult of human neuropathological conditions. Therefore, we characterize astrocyte pathological and heterogeneous populations in different cortical regions of patients with complicated and severe brain trauma associated with subdural, extradural haematoma or hygroma (a subdural body of cerebrospinal fluid (CSF), without blood, believed to be derived from chronic subdural haematomas). Additionally, we have compared the electron microscopic features of astrocyte subtypes in complicated human traumatic brain injuries with those reported in a large variety of nervous and mental diseases, and in vivo and in vitro experimental conditions, in an attempt to establish a link between basic and clinical neuroscience, and to gain a better insight into the real significance of heterogeneity of astrocytes that occur at the immediate site of severe and complicated human brain injuries. This comparative extrapolation of findings will allow us to explore new and common pathogenetic mechanisms, and to study new therapeutic strategies.

\section{Light and electron microscopy fixation procedures for human cortical biopsies}

Two to five $\mathrm{mm}$ thick cortical biopsies from the perifocal area of a traumatic lesion of the frontal and parietal region were taken by the neurosurgeon, and immediately fixed in the neurosurgical room in $4 \%$ glutaraldehyde-0.1 $\mathrm{M}$ phosphate or cacodylate buffer, $\mathrm{pH} 7.4$, at $4^{\circ} \mathrm{C}$, in order to avoid delay fixation. After 2 hours of the glutaraldehyde fixation period, the cortical biopsies were divided in our laboratory into approximately $1 \mathrm{~mm}$ slides, and observed under a stereoscopic microscope to check the quality of fixation of the sample, the glutaraldehyde diffusion rate, and the brownish coloration of the surface and deeper cortical regions, indicative of good glutaraldehyde fixation by the immersion technique. Immersion in fresh glutaraldehyde solution of $1 \mathrm{~mm}$ 
slices was secondarily done for 2 hours after eliminating the remaining blood from the cortical biopsy by washing in similar $0.1 \mathrm{M}$ phosphate or cacodylate buffer, $\mathrm{pH} 7.4$, to avoid oxidation of the primary fixative solution. Secondary fixation in $1 \%$ osmium tetroxide $0.1 \mathrm{M}$ phosphate buffer, $\mathrm{pH} 7.4$, was carried out for $1-2$ hours at $4^{\circ} \mathrm{C}$. Black staining of the cortical slices also was observed under a stereoscopic microscope to determine the osmium tetroxide diffusion rate and quality of secondary fixation. The samples were then rinsed for 5 to 10 minutes in phosphate or cacodylate buffer of similar composition to that used in the fixative solution, dehydrated in increasing concentrations of ethanol, and embedded in Araldite or Epon. For proper orientation during the electron microscope study and observation of cortical layers, approximately 0.1 to $1 \mu \mathrm{m}$ thick sections were stained with toluidine blue and examined with a Zeiss photomicroscope. Light microscope study of neurons, glial cells, and blood-brain barriers was performed. Ultrathin sections, obtained with Porter-Blum and LKB ultramicrotomes, were stained with uranyl acetate and lead citrate, and observed in a JEOL 100B transmission electron microscope (TEM) at magnifications ranging from 20,000 to $90,000 \times$. Approximately one hundred electron micrographs were taken of each cortical biopsy. Those cortical biopsies with delayed and poor fixation, due to inactivation of the primary fixative for the presence of tissue blood, were discarded. Since poor or delayed fixation of brain parenchyma exhibits features quite similar to those observed in an oedematous tissue, in each case we critically differentiate between true pathology and fixation artefacts. The different submicroscopic features that characterize moderate and severe brain oedema allowed us to discard fixation artefacts, mainly when analysing substructures such as the multilamellar arrangement of myelin layer [23]. To characterize a subpopulation of astrocytes we assemble a montage of serial electron micrographs to analyse the entire cell body and processes. A clear distinction between astrocytes and oligodendrocytes was made in each case examined.

\section{Heterogeneity of astrocyte population after severe and complicated brain injuries}

The following astrocyte populations are found at the light and electron microscopic levels in the oedematous human cerebral cortex associated with complicated brain trauma: reactive clear and dense swollen astrocytes, reactive hypertrophic astrocytes, lipofuscin-rich astrocytes, glycogen-rich and glycogen-depleted astrocytes, and phagocytic astrocytes $[28,30,32]$.

\section{Clear oedematous astrocytes in light and electron microscopy}

Semithin plastic sections stained with toluidine blue show the presence of clear and dense notably swollen astrocytes at the perineuronal, interfascicular, and perivascular localizations. They appear surrounded by notably enlarged extracellular spaces (Fig. 1A), which feature the status spongiosus of brain parenchyma. Perineuronal astrocytes appear intimately applied to shrunken and ischaemic neuronal bodies (Fig. 1B). Binucleated and multinucleated astrocytes, indicating astrocyte proliferation, are also observed (Fig. 1C). Electron micrographs show the clear astrocytes characterized by an electron lucid cytoplasm matrix, widened rough endoplasmic reticulum, clear and swollen mitochondria with dislocated or fragmented cristae, lysosomes, phagolysosomes, and glycogen granules [24,26] (Fig. 1D).

Very severely oedematous clear astrocytes show lacunar or vacuolated enlargement of rough endoplasmic reticulum, an increased amount of glial filaments, fragmentation of Golgi apparatus, and numerous lysosomes (Fig. 2A).

Oedematous astrocyte were also reported by Ito et al. [67] in focal cortical infarction, and by Kuchiwaki et al. [79] in cytotoxic brain oedema.

These astrocytes are characterized by robust processes containing bundles of glial filaments (Fig. 2B).

Similar cable-like bundles of glial filaments were reported by Graeber and Kreutzberg in facial nerve axotomy [60].

Figures 2C and 2D show "control" electron micrographs of the apparently normal astrocyte cell body and processes from a patient with anomaly of the anterior cerebral artery. It is important to keep in mind that brain oedema is produced as soon as the brain is exposed to the air during neurosurgery following opening of the meningeal covering. The neighbouring neuropil shows the best ultrastructural preservation obtained with the immediate glutaraldehyde-osmium fixation procedure of cortical biopsies in the neurosurgical room. Note the integrity of subcellular structures of apparently normal nerve cell bodies and processes, the conti- 

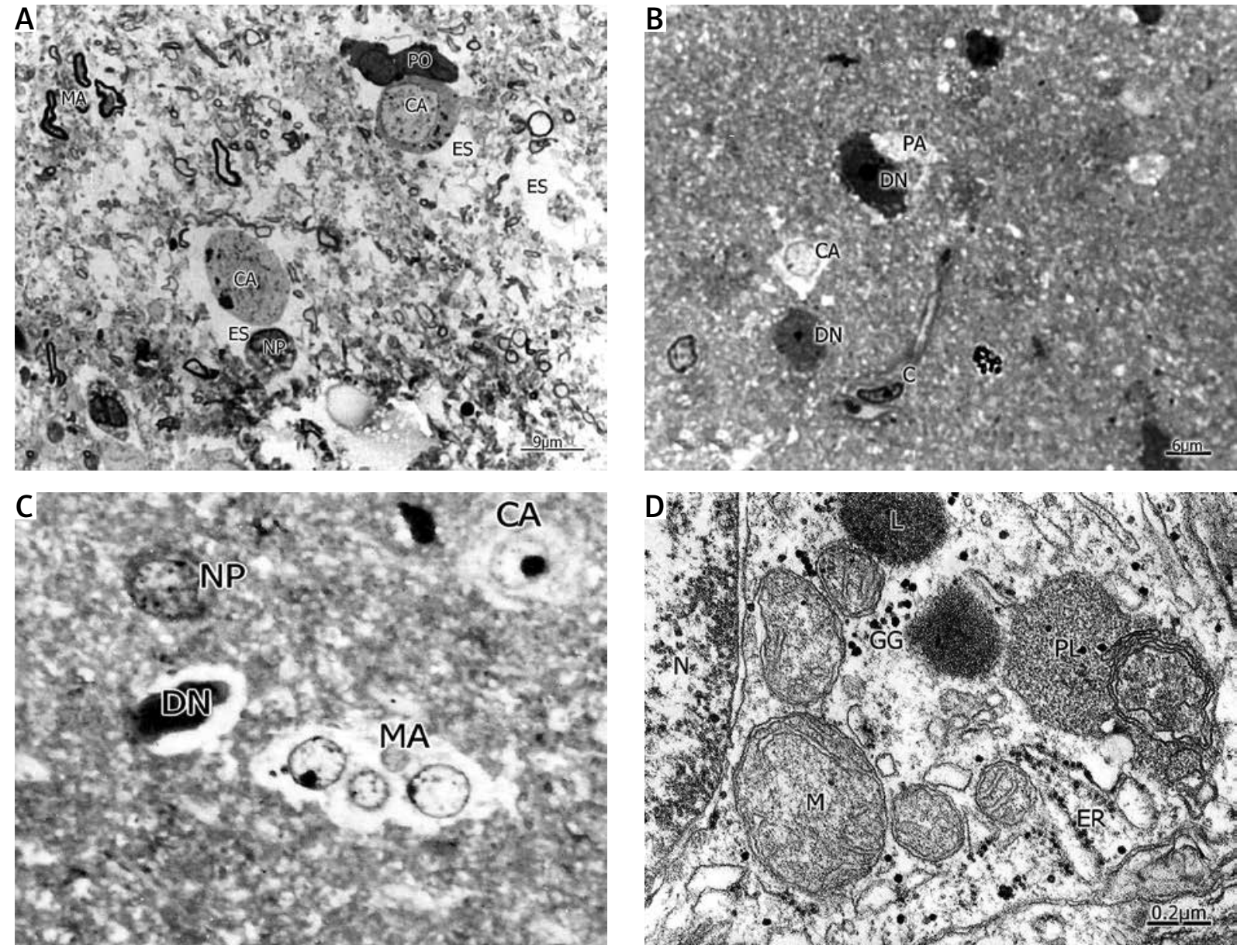

Fig. 1. A) Brain trauma. Subdural haematoma. Left parietal cortex. Light microscopy of a toluidine blue stained semithin plastic section exhibiting notably swollen clear astrocytes (CA) surrounded by enlarged extracellular space (ES). A non-pyramidal neuron (NP), an ischaemic and dense perineuronal oligodendroglial cell (PO) and degenerated myelinated axons (MA) are seen in the neighbouring neuropil. Note the status spongiosus of brain parenchyma. B) Similarly stained semithin plastic section showing swollen perineuronal (PA) and clear interfascicular astrocytes (CA) surrounding dense and ischaemic neurons (DN). A longitudinally sectioned capillary (C) also is noted. C) Semithin plastic section depicting a multinucleated astrocyte (MA). A dark neuron (DN), a clear non-pyramidal neuron, and a swollen clear astrocyte (CA) are distinguished. D) Electron micrograph of a swollen and clear astrocyte (CA) characterized by an electron lucid cytoplasmic matrix, dense mitochondria $(M)$ with fragmented cristae, dilated rough endoplasmic reticulum (ER) and nuclear (N) envelope, glycogen granules (GG), and a phagolysosome (PL).

nuity of limiting plasma membrane profiles, glial filaments, and the membrane-to-membrane, $20 \mathrm{~nm}$ in width, non-dilated extracellular space separating nerve cell processes in the neuropil [24].

\section{Brain trauma induces dense swollen reactive astrocytes}

Dense, swollen astrocytes are easily identified by the higher electron density of their cytoplasmic matrix. They exhibit vacuolization of rough endoplasmic reticulum, detachment of associated ribosomes, plasma membrane disruption, clear and swollen mitochondria with cristae fragmentation and dissolution, and bundles of glial filaments extended toward the vacuolated astrocyte processes [28,29] (Figs. 3A and 3B).

Clear and dense astrocyte swelling also have been widely reported by Allen et al. [5] after high 

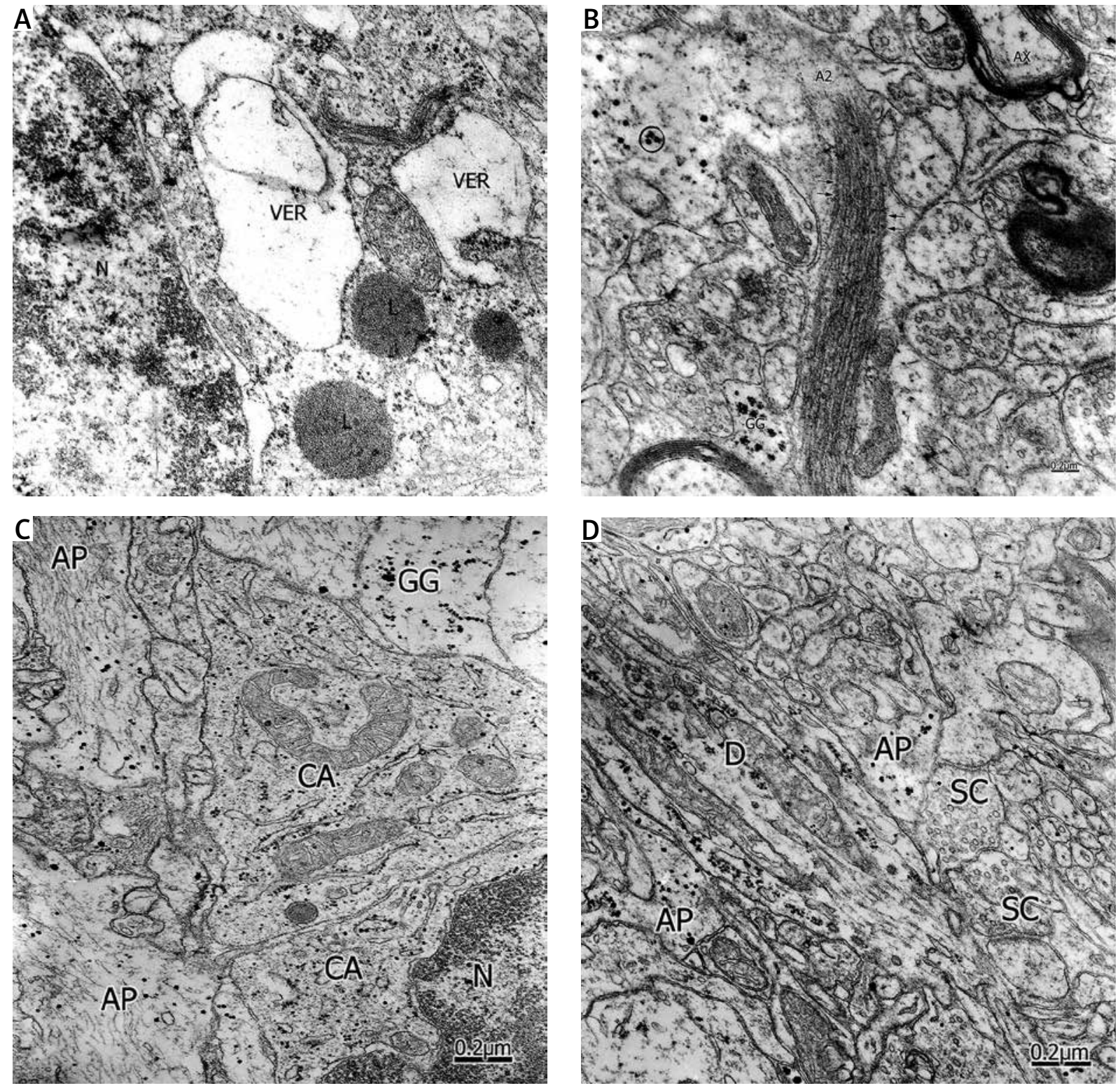

Fig. 2. A) Brain trauma. Subdural haematoma. Left parietal cortex. Clear and notably swollen astrocyte showing irregular enlargement of nuclear $(N)$ envelope, vacuolated rough endoplasmic reticulum (RER), and lysosomes (L). B) Clear astrocyte (CA) showing alpha-type glycogen granules (circle), and a robust astrocyte process containing bundles of glial filaments (short arrows). A small astrocyte process, containing alphatype glycogen granules (GG), is seen enveloping a degenerated myelinated axon. Another degenerated axon ( $A X)$ is seen at the upper right side of the figure. C) Electron micrograph of a "control" clear astrocyte cell body (CA) and processes (AP) of a cortical biopsy taken and fixed in the neurosurgical room from a patient with malformation of the anterior cerebral artery, and using the same glutaraldehyde-osmium fixation protocol employed in the cortical biopsies with traumatic brain injuries. Note better ultrastructural preservation of nuclear envelope, mitochondria, and bundles of glial filaments at the astrocyte processes. A glycogen-rich astrocyte process containing beta-type glycogen granules (GG) is also well preserved. D) "Control" neuropil of the same patient displaying optimal preservation of dendrites (D), astrocyte cytoplasm (A), and synaptic contacts (SC). Note the normal appearance of membrane-to-membrane spaces, and the absence of widened extracellular spaces. 

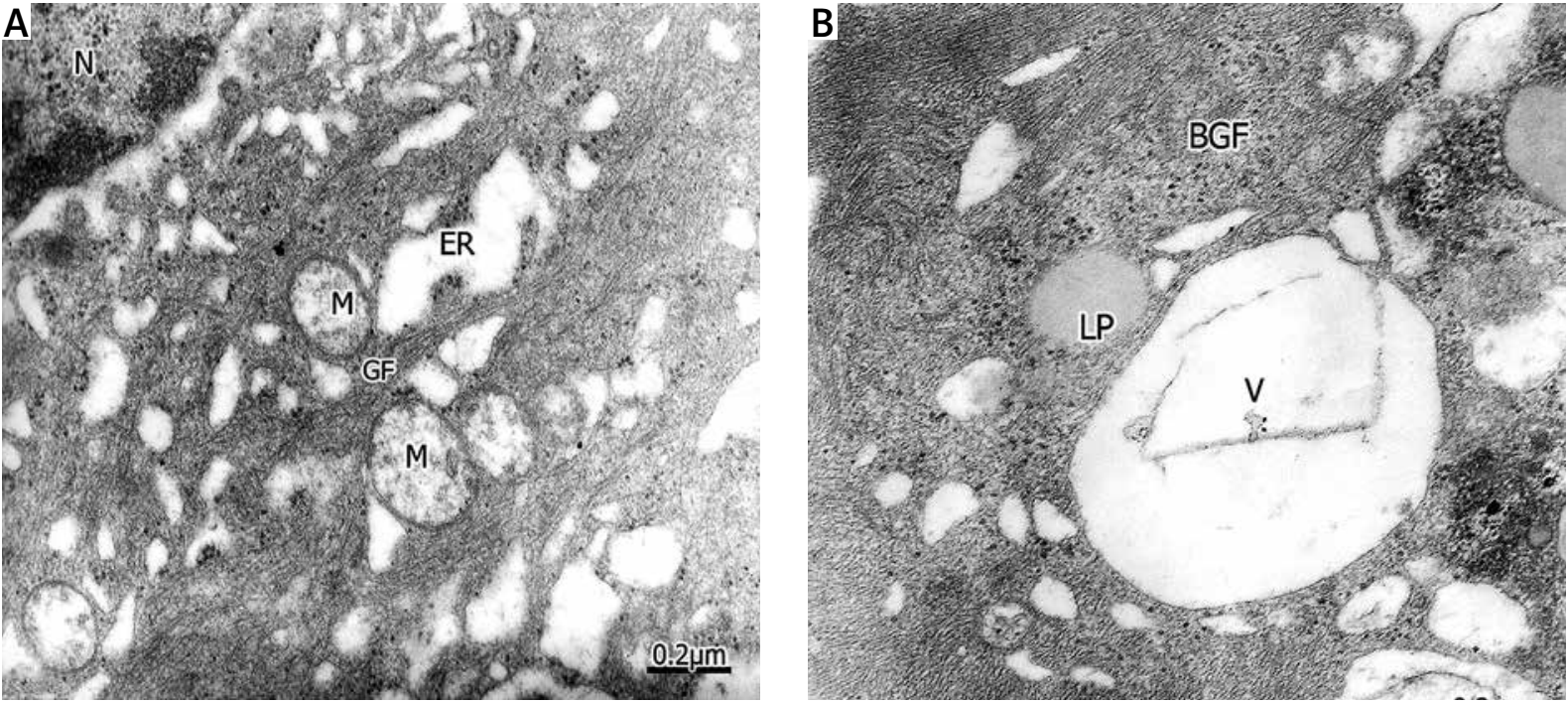

Fig. 3. A) Dense and swollen astrocyte displaying vacuolated rough endoplasmic reticulum (ER) with detachment of associated ribosomes, clear notably oedematous mitochondria $(M)$ with granular disintegration of mitochondrial cristae, bundles of microfilaments, and notably enlarged nuclear $(\mathrm{N})$ envelope. B) Dense astrocyte process containing bundles of glial filaments (BGF) at sublemmal localization, and sparse betatype glycogen granules, large vacuoles (V), and low electron dense liposomes (LP).

velocity penetrating head injuries, Bullock et al. [15] following human cerebral contusion, Dietrich et al. [48] after fluid percussion brain injury, Fujisawa et al. [56] using a rat model of subdural haematoma, Mathew et al. [94] in an experimental model of contusion and focal cortical injury, Kuroiwa et al. [80] during early ischaemia, and by non-traumatic neuropathological conditions, such as Matyja et al. [96] in amyotrophic lateral sclerosis (ALS), a model of slow glutamate excitotoxicity. Similar findings have also been observed in vitro in a variety of experimental conditions, such as swelling-induced release of glutamate, aspartate, and taurine from astrocyte cultures, hypoosmotic media, high $\mathrm{K}^{+}$, high glutamate, ethanol, free fatty acids, lacto-acidosis and acidbase exchange [7,73-75], and the role of $\mathrm{Na}^{+}, \mathrm{K}^{+}$and $\mathrm{Cl}^{-}$cotransporters in brain ischaemia [39].

\section{Interfascicular and swollen perisynaptic astrocyte processes}

The clear and swollen astrocytic processes containing beta type-glycogen granules can be traced in the neuropil in moderate oedema far from the traumatic perifocal region, where they appear surrounding the synaptic contacts, swollen and bead-shaped dendritic profiles, and degenerated myelinated axons. These swollen astrocyte processes compress and indent the degenerated myelinated axons. At the level of this compression zone, the degenerated myelinated axons appear constricted with distorted and vacuolated myelin sheath [23] (Figs. 4A and 4B).

The presence of notably swollen astrocytes and degenerated myelinated axons has been described previously by Graeber and Kreutzberg [60] following facial nerve axotomy, by Gilmore et al. [59] after sciatic axotomy, and by Murray et al. [103] in dorsal root or peripheral nerve lesions.

In those patients with very severe brain oedema, located at the perifocal area, the haematogenous oedema fluid rejects the astrocyte perisynaptic cytoplasm, and the pre- and postsynaptic endings and the synaptic cleft appear in direct contact with the extracellular space [29,31] (Fig. 4C).

These findings indicate that astrocytes lost both the prime location to receive synaptic information from released neurotransmitters and the neurotransmitter receptor expression in response to injury [104]. Additionally, the diffusion of nerve impulse transmission to the extracellular space indicates loss of astrocyte modulation of extracellular space [6]. If we consider that the perisynaptic astrocyte should be viewed as an integral modulatory element of the tripartite synapse [6], we are really dealing with dissociated tripartite synapses. 

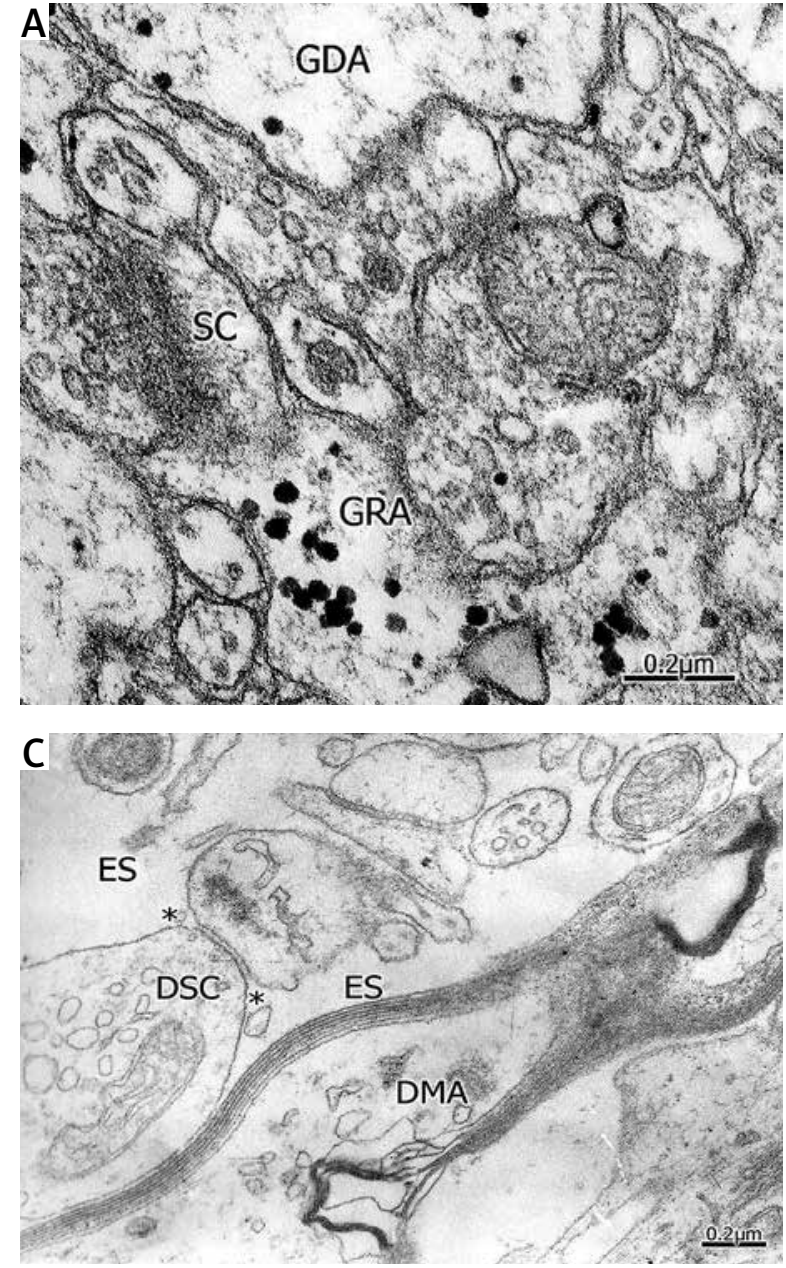

\section{Hypothesis on the biopathological significance of absent perisynaptic astrocyte ensheathment}

Our electron microscopic studies suggest that in the perisynaptic glial-synaptic contact dissociation process, the specific functions of astrocytes in synaptic transmission, such as the ability to take up and metabolize neurotransmitters, are disrupted - for example, glutamate uptake and glutamate release at the synapses that they envelop, to protect these synapses against inappropriate activation by excess transmitter released or regulate synaptic transmission [6], and also inactivate neurotransmitters [92]. Such modulatory regulation or inactivation is disrupted by traumatic brain oedema. The alteration of these specific functions would help to explain the contribution of pathological astrocytes to development of neurobehavioral disorders, such as loss of consciousness, neurological deficits, and

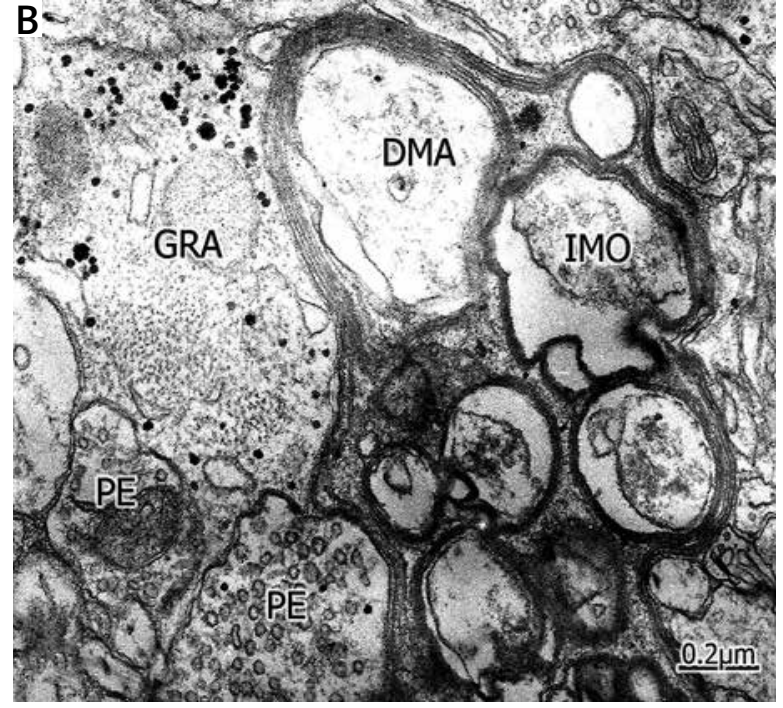

Fig. 4. A) Brain trauma. Epidural haematoma. Right parietal cortex. Perisynaptic glycogen-rich (GRA) and glycogen depleted (GDA) astrocyte processes located in an area of moderate brain oedema surrounding an axo-dendritic contact (SC). B) Glycogen-rich and filamentous astrocyte (GRA) cytoplasm intimately applied to presynaptic endings (PE) and to a degenerated myelinated axon (DMA) containing inner myelin ovoids (IMO). C) Degenerated axodendritic contact (DSC) devoid of perisynaptic layer located in a severely oedematous area. The synaptic cleft (asterisks) appears in direct contact with the enlarged and electron lucid extracellular space (ES) containing non-proteinaceous oedema fluid. Note the neighbouring and longitudinally section of a degenerated myelinated axon (DMA).

seizures [27,31]. In addition, Uranova et al. [137] have described ultrastructural alterations of both synaptic contacts and astrocytes in the postmortem caudate nucleus of schizophrenic patients, suggesting that perisynaptic ensheathment dissociation is not a specific finding of human traumatic brain injuries.

\section{The glio-basal dissociation process in severe traumatic brain injuries}

At the light microscopy level, clear and dense perivascular astrocytes appear mostly attached to the outer surface of the capillary basement membrane mainly in areas of moderate, and some regions of severe oedema located far from the traumatic perifocal region [25,37] (Fig. 5A and 5B). 

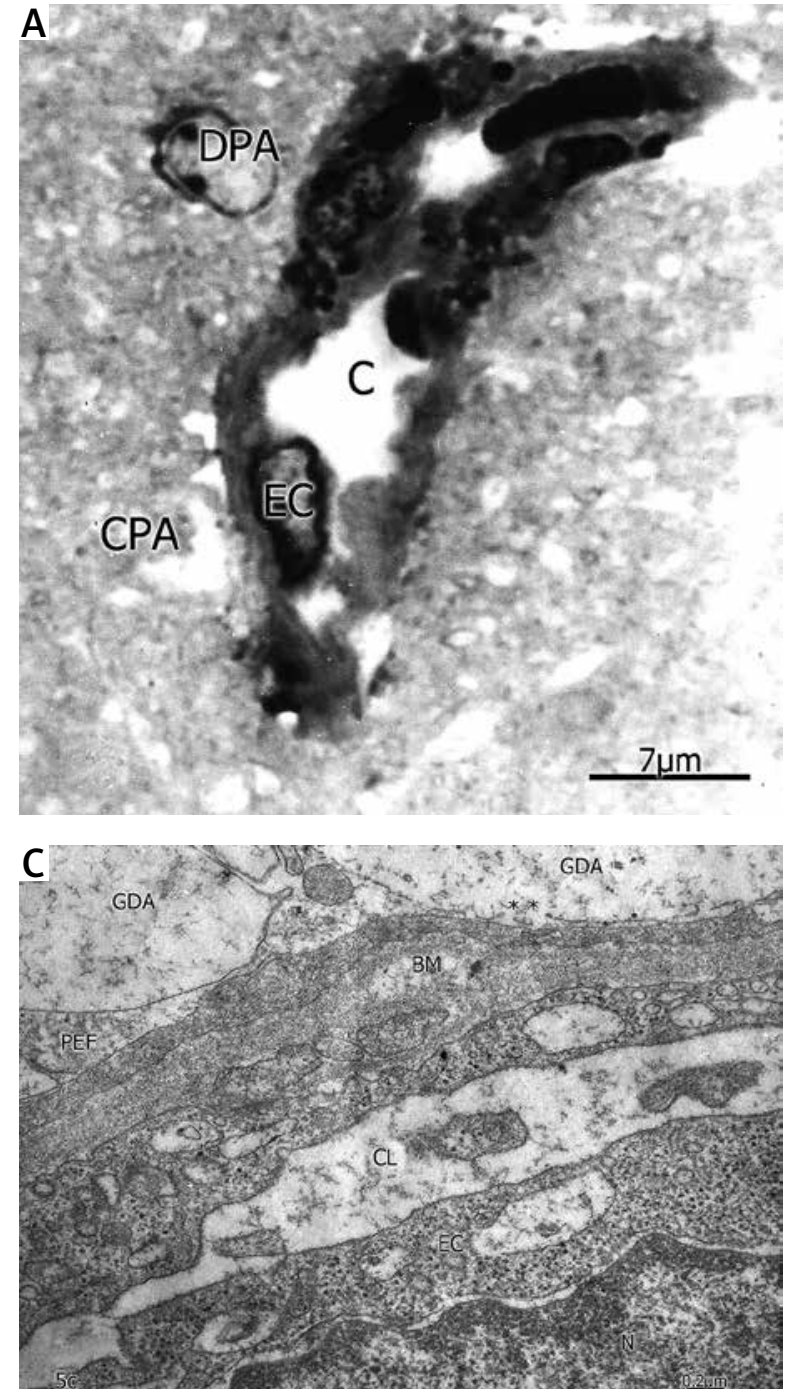

In severe and complicated brain injuries, a gliobasal dissociation process occurs and a separation of astrocyte end-foot limiting plasma membrane from the capillary basement membrane is observed (Fig. 5C). Additionally, the astrocyte perivascular end-feet are fragmented and remnants of their limiting plasma membranes are observed. Extensive areas of the capillary basement membrane devoid of astrocytic end-feet appear in direct contact with the enlarged extracellular space containing electron lucid or proteinaceous oedema. These findings demonstrate the absence of the glial cell component of the blood-brain barrier, and indicate the glial barrier dysfunction induced by the traumatic brain oedema [37], and interruption of the route between capillaries, astrocytes and the neuronal membranes by which metabolic substrates reach the neurons

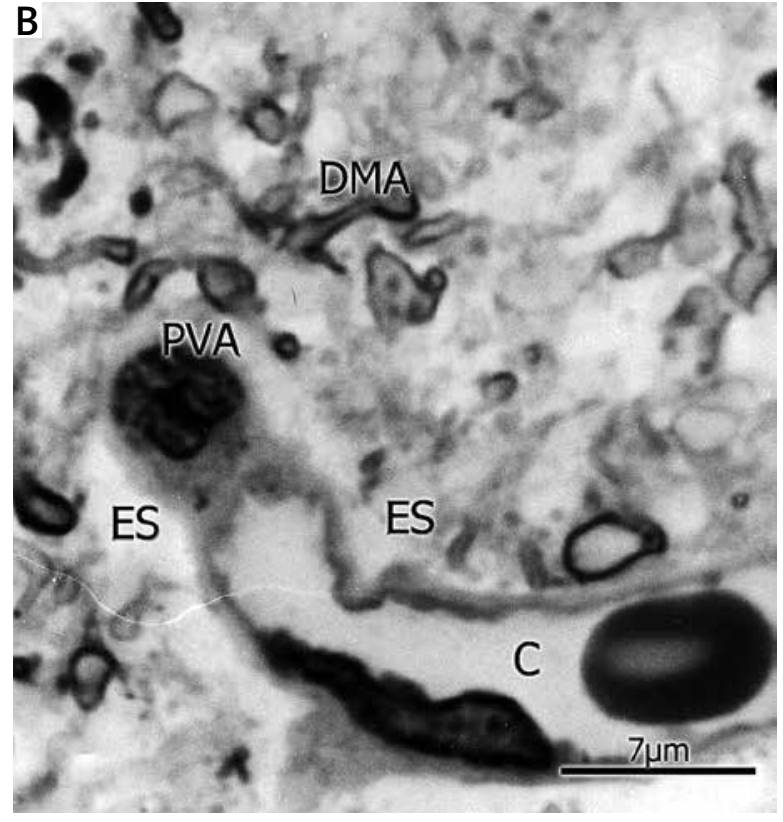

Fig. 5. A) Brain trauma. Subdural haematoma. Right parietal cortex. Light microscopy of a toluidine blue-stained semithin plastic section of a longitudinal section of cortical capillary in a moderate oedematous region showing swollen and clear perivascular astrocytes (CPA), and a dense perivascular astrocyte (DPA) attached to the capillary outer surface. The endothelial cell (EC) and the capillary lumen (C) are also seen. B) Shows a semithin section of a longitudinally sectioned capillary (C) in a severely oedematous region showing a swollen and clear perivascular astrocyte (PVA) attached to the capillary outer surface, and surrounded by large extracellular spaces (ES). Numerous degenerated myelinated axons (DMA) are also seen in the spongy neuropil. C) Electron micrograph of extremely swollen and glycogen-depleted perivascular astrocytic end-feet (GDA) localized in a severely oedematous area and dissociated from the thickened capillary basement membrane (BM) by proteinaceous oedema fluid (PEF) and a thin layer of dense astrocyte cytoplasm. Note the discontinuities of the limiting plasma membranes (asterisks). A swollen and vacuolated endothelial cell (EC) and the capillary lumen (CL) are also seen.

$[25,37,139]$. Subsequently, vasogenic and cytotoxic oedema are superimposed, and degeneration and death of pyramidal and non-pyramidal nerve cells 

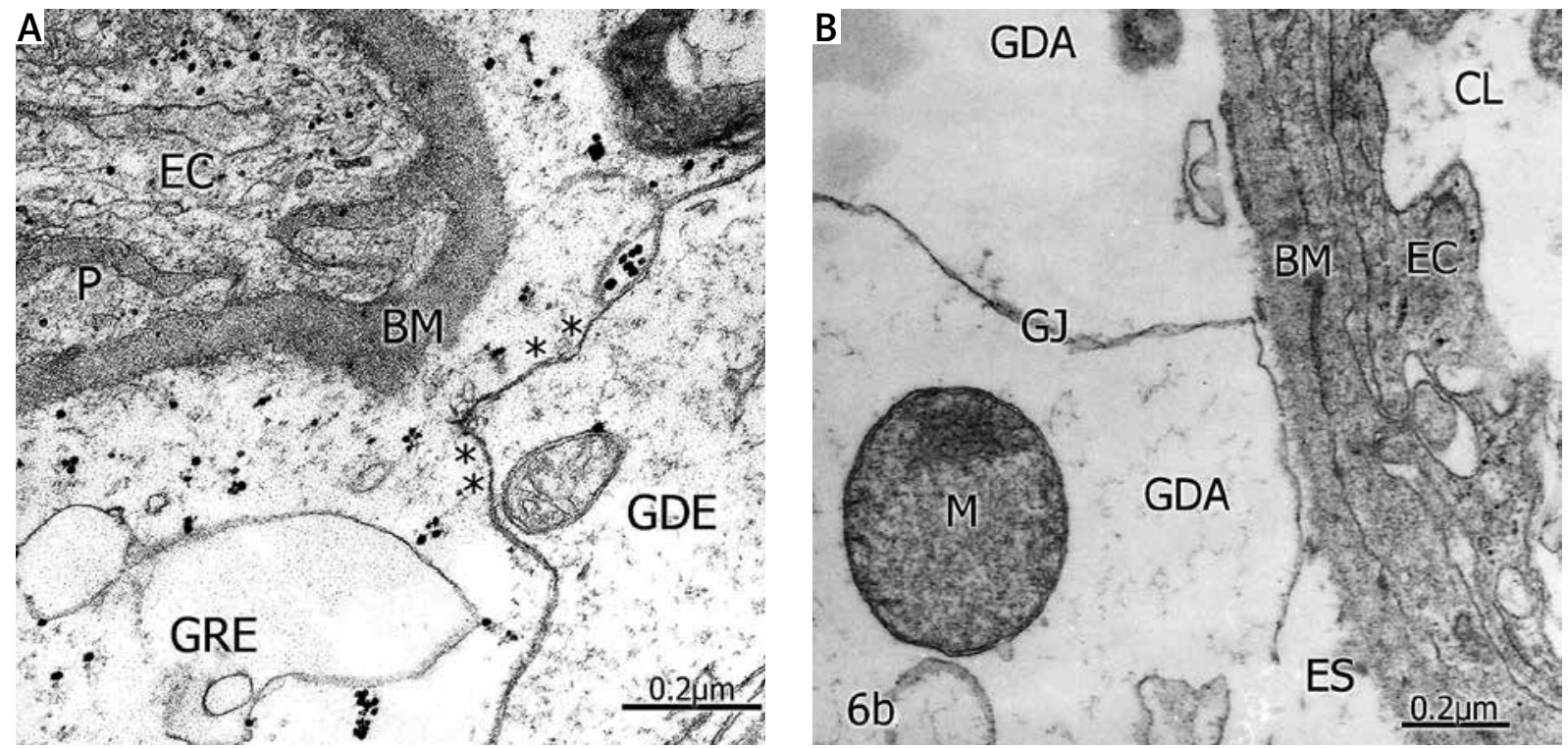

Fig. 6. A) Brain trauma. Subdural haematoma. Glycogen-depleted (GDE) and glycogen-rich (GRE) perivascular astrocytic end-feet appear applied to the outer surface of the capillary basement membrane (BM) in a moderate oedematous region. The GRE exhibits beta-type glycogen granules and vacuoles. The gap junction between both astrocyte end-feet shows areas of fused astrocyte confronted limiting membranes (asterisks) and absence of the intercalated extracellular space. A pericyte (P) and endothelial cell (EC) are also visualized. B) Extremely swollen glycogen-depleted perivascular astrocytic end-feet (GDA) dissociated from the capillary basement membrane (BM) by the oedema fluid and exhibiting discontinuities of the limiting membrane. A swollen and degenerated mitochondrion $(M)$ is observed. Note the enlarged extracellular space (ES), and the denuded capillary basement membrane outer surface (BM). The gap junction (GJ) shows fused and disrupted confronted membranes. The vacuolated endothelial cells (EC), and the capillary lumen $(\mathrm{CL})$ are also distinguished.

occur [25,37]. Similar findings were reported by Ito et al. [67] in experimental ischaemic brain oedema in gerbils.

\section{Astrocytes' supply of substrates of glycogen metabolism to ischaemic neurons and oligodendroglial cells}

Glycogen-rich and glycogen-depleted perivascular astrocyte end-feet are found in severe traumatic brain injuries [30]. The glycogen-rich perivascular astrocyte end-feet show enlarged vesicular and vacuolar profiles of endoplasmic reticulum, and betaand alpha-type glycogen granules. In contrast, glycogen-depleted astrocyte end-feet are distinguished by a scarce amount or absent isolated beta- and gamma-type glycogen granules, characterized according to Drochman' s classification [49]. This classification allowed us to distinguish among beta or monogranular, alpha or in rosette clusters, and gamma or mini type, according to glycogen granular size and degree of aggregation (Fig. 6A and 6B).

In physiological conditions there is no evidence for transfer of glycogen substrate energy from glial cell stores to neurons [42]. Our electron microscopic findings suggest that glycogen accumulation and breakdown are induced by the severity of traumatic brain injuries [30]. The fact that both glycogen-rich and glycogen-depleted astrocyte perivascular processes are simultaneously found strongly suggests the hypothesis that in human brain trauma astrocytes exert a neuroprotective action supplying substrates of glycogen metabolism for the survival of ischaemic neurons and oligodendroglial cells. In support of our hypothesis is the fact that glycogen accumulation after an initial decrease is a distinctive feature of astrocytes responding to injury [64]. According to Magistreti et al. [89], astrocytes may help neurons with their energy requirements during periods of activity. 


\section{Enlargement, fusion and disruption of interastrocytary gap junctions induced by the traumatic agent}

At the level of interastrocytary gap junctions (gap junctions localized between two neighbouring astrocyte end-feet belonging to the same or to different clear or dark perivascular astrocytes), the severe traumatic injury induces widening of confronted astrocyte end-feet limiting membranes and enlargement of extracellular space between the astrocyte end-feet, or they appear either fused or disrupted by the notably swollen astrocyte end-feet [22,26] (Fig. 6A and 6B).

There is a relationship between swollen capillary endothelial cells and swollen perivascular astrocytes. The open endothelial junctions [35] and the increased transendothelial vacuolar and vesicular transport [32] discharge the brain oedema fluid into the thickened basement membrane, and into the astrocyte perivascular end feet [37].

These findings indicate blood brain barrier breakdown and the genesis of vasogenic brain oedema in severe human brain trauma. These findings also tend to demonstrate that in human traumatic brain oedema, the connecting hemichannels of each confronting astrocytic end-foot process forming the gap junctions $[46,89,104,121]$ are set apart or damaged with subsequent disruption of connexin proteins. In normal physiological conditions, astrocytes in vitro modulate the blood-brain barrier permeability, but there is no correlation with alterations of tight junction protein from the cellular contacts. However, as previously demonstrated by Hossain et al. [66], astrocytes respond to an ischaemic insult reorganizing their gap junctions. Theriault et al. [133] described alteration of connexin 43 and astrocytic gap junctions after acute compression injury. Nerve cell injury causes large intracellular increase in intracellular $\mathrm{K}^{+}$and $\mathrm{Ca}^{2+}$, which could lead to astrocytic uncoupling [108]. In addition, intracellular acidification mediated by lactate also results in irreversible astrocytic uncoupling [3]. Additionally, Li et al. [84] reported the phosphorylation status of gap junctions and connexin 43 in rat brain after cerebral focal ischaemia.

The above-mentioned findings on damaged astrocytic gap junctions suggest a whole alteration of the pan-glial syncytium postulated by Rash et al. [122] and Li et al. [84], or an interruption of the gap junction wiring described by Dermietzel et al. [46]. In addition, it would mean an alteration of the coordinating role of gap junctions in motor behaviour [71].

\section{Dense and reactive hypertrophic astrocytes}

Hypertrophic astrocytes are observed at the interfascicular level at the neuropil and in perivascular localization. Their perivascular end-feet can be observed attached to the capillary basement membrane. They are characterized by increased cytoplasmic matrix density, distended rough endoplasmic reticulum profiles, swollen mitochondria, fragmentation of Golgi apparatus, and presence of alpha- and beta-glycogen particles. Close examination of the cytoplasm at higher magnification shows increased numbers of glial filaments, microtubules, and numerous round and lobulated lysosomes. They exhibit robust and extended processes in the neuropil containing compact bundles of glial filaments $[26,28,29]$ (Fig. 7A).

These types of astrocytes have also been found by Kaur et al. [70] after a non-penetrative blast. However, hypertrophic astrocytes seem to be an unspecific population present in traumatic brain injuries since they have been described in a large variety of distinct human nerve pathological entities, and in experimental animal models, such as those reported by Ludowyk et al. [87] in chronic experimental autoimmune encephalitis in aged rats, Khurgel and Ivy [72] in kindling-induced seizures, Krsulovic et al. [78] in nerve cells of taiep rats, and by Harsan et al. [63] in dysmyelinated jimpy mouse brain. The mouse jimpy mutation of the $\mathrm{X}$-linked proteolipid protein (PIp) gene causes dysmyelination and premature death of the mice. The established phenotype is characterized by severe hypomyelination, increased numbers of dead oligodendrocytes and astrocytosis. This astrocytosis exhibits similar features as in the case of the astrocytes described above. Therefore, dense and reactive hypertrophic astrocytes are not a subpopulation of astrocytes specifically induced by severe and complicated human brain injuries.

Dark astrocytes, which should be considered as a variety of hypertrophic astrocytes, have been found by Gallyas et al. [57], and by Tóth et al. [136] after compressive or concussive head injuries. These reactive astrocytes with dense processes are GFAP immunoreactive [51-53], and have been co-labelled by antibodies to GFAP and vimentin [54]. For further details the reader is referred to the elegant review of Malhotra et al. [91] on reactive astrocytes. 

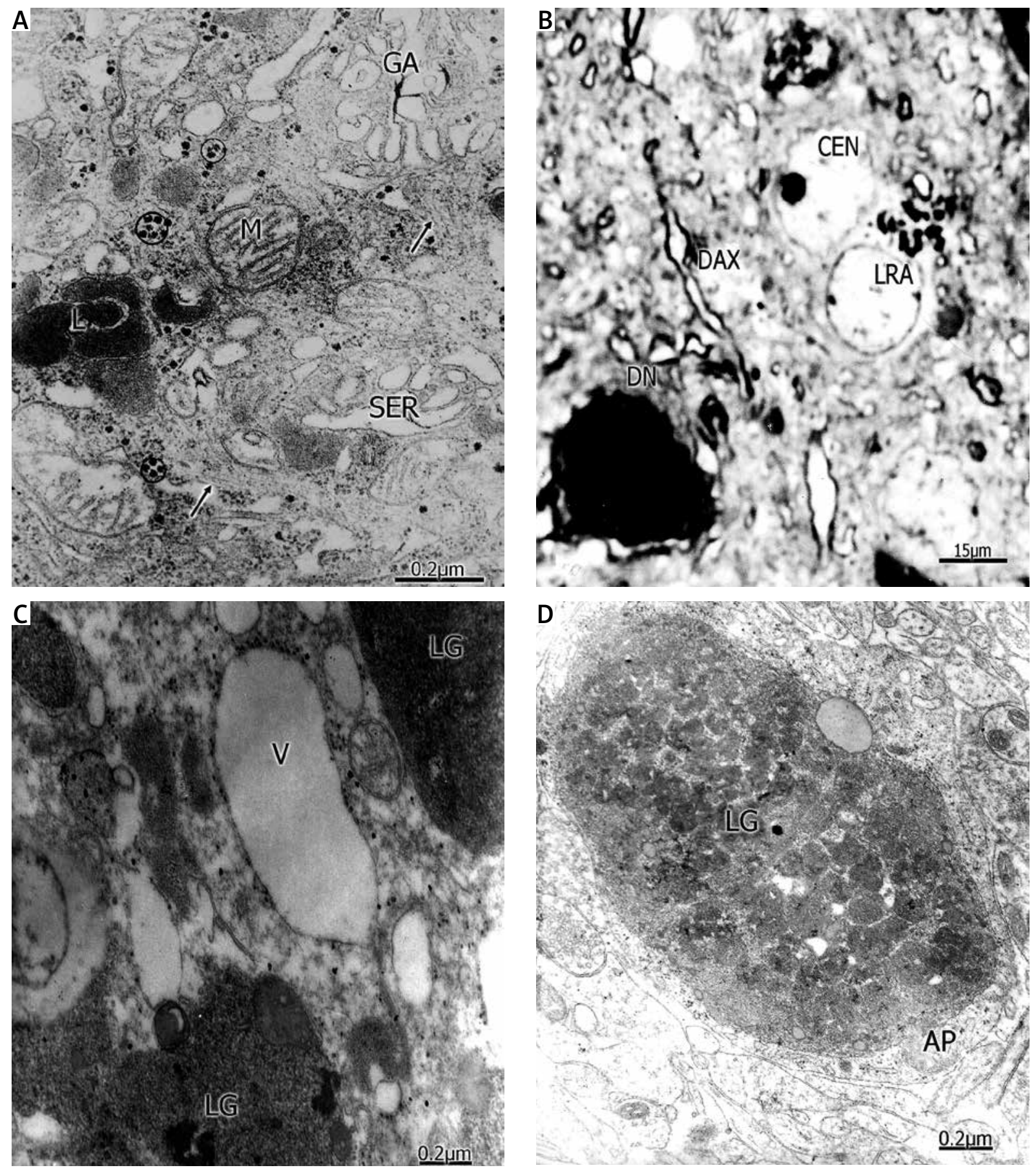

Fig. 7. A) Brain trauma. Subdural haematoma. Left parietal cortex. Electron micrograph of a dense hypertrophic astrocyte showing numerous canaliculi and vesicles of smooth endoplasmic reticulum (SER), multiple rosettes of multigranular or alpha-type glycogen particles (circle), clear and swollen mitochondria (M), lobulated lysosomes (L), fragmented Golgi apparatus (GA), and microfilaments (arrows). B) Brain trauma. Subdural haematoma. Frontal cortex. Light microscopy of a semithin section stained with toluidine blue showing a swollen and lipofuscin-rich clear astrocyte (LRA) surrounding a clear oedematous neuron (CEN). A dark ischaemic neuron (DN) and a degenerated myelinated axon (DAX) are also distinguished. C) Electron micrograph of a lipofuscin-rich astrocyte cytoplasm exhibiting lipofuscin granules (LG) and vacuoles (V). D) Lipofuscin-rich astrocyte process (AP) containing a huge lipofuscin granule (LP). 


\section{Lipofuscin-rich astrocytes favour the aging process and neuronal degeneration in traumatic brain injuries}

In traumatic brain injuries, accumulation of lipofuscin granules has been found in the astrocyte body and processes [32] (Fig. 7B, 7C and 7D).

This lipofuscin accumulation has been widely reported in normal aging subjects [100]. Although age is considered an important factor reducing astrocyte reactivity, in aging patients with severe brain trauma, increased reactivity of astrocytes was observed characterized by a large amount of lipofuscin-rich astrocytes. The significance of lipofuscin accumulation for astrocyte biopathology is a subject that remains relatively poorly defined in the world literature. Our studies have demonstrated that lysosomes coexisting with an increased amount of lipofuscin granules are observed in young and adult patients with brain trauma, tumours and vascular anomalies, implicating a dysfunction of the endolysosomal system in astrocytes [32]. We have also reported lipofuscin granules in neonate and infant patients with congenital hydrocephalus [32], suggesting that lipofuscin formation is a life span process in immature and mature astrocytes, and not only due to the aging process, as it has been classically conceptualized. The neurodegeneration associated with lipofuscin accumulation may be caused by that accumulation, and induces astrocyte activation. Lipofuscin and ceroid are usually held responsible for impaired cellular performance, via oxidative damage and the irreversible accumulation of fluorescent products of lipid peroxidation. The participating evidence of free radical oxidative interactions in promoting astrocyte injury in such conditions as brain trauma, ischaemia, toxicity, and in neurodegenerative diseases such as Parkinson' s disease, Alzheimer' $s$ dementia, multiple sclerosis, and lipofuscinosis, is growing and accumulating, and favouring the idea of an overall spectrum of an altered endosomal/lysosomal system. Accumulation of heterogeneous non-degraded macromolecules in dysfunctional lysosomes and autolysosomes ultimately leads to early-onset apoptotic death with subsequent activation of astrocytes [111]. The general hypothesis, as developed from chronic neurodegenerative diseases [14,16], is that astrocyte activation occurs in juvenile neuronal ceroid lipofuscinosis (JNLC) and Batten disease. Additionally, the role of peroxy radicals or their products formed by lipoperoxidation of polyunsaturated fatty acids has also been implicated [13].

In spite of recent advances in immunohistochemical identification of biochemical markers, the ultrastructural identification of lipofuscinic pigments remains the gold standard to identify neuronal ceroid lipofuscinosis ( $\mathrm{NCL}$ ), together with the clinical aspects and respective gene defects [14]. Neuronal cell cultures offer a good model to study systematically lipofuscin' s impact on astrocyte biopathology.

\section{Traumatically reactive astrocytes phagocytose synaptic contacts, myelinated axons and undifferentiated nerve cell debris}

Clear and swollen dense perineuronal phagocytic astrocytes can be seen engulfing remnants of degenerated myelin sheath, myelin ovoids, degenerated myelinated axons, and entire degenerated axo-dendritic contacts, and fragments of nerve cell debris.

These two types of phagocytic astrocytes are frequently found in traumatic brain oedema: the clear type characterized by lamellar processes containing osmiophilic vesicles, as previously described by Gonatas et al. [62] (Fig. 8A), and a second type: the dark phagocytic astrocytes $[26,28]$. Figure $8 B$ shows a clear phagocytic astrocyte cytoplasm with osmiophilic vesicles in the neuropil engulfing a presynaptic ending. These findings indicate the participation of phagocytic astrocytes in the removal of degenerated nerve cell substructures in the traumatic oedematous human cerebral cortex $[28,29]$.

Table I below summarizes the features of astrocyte changes in moderate and severe oedema.

\section{Traumatic brain oedema induces disruption of astrocyte plasma membrane and cytomembranes}

The physical stress elicited by the intensity of the traumatic agent induces rupture of the astrocyte plasma membrane, nuclear membranes, cytomembranes and Golgi apparatus, and perivascular astrocyte end-feet exhibit membrane defects induced by decreased $\mathrm{Na}^{+}-\mathrm{K}^{+}-$ATPase activity exerted by the trauma [41], and changes in the extracellular ion $\mathrm{Na}^{+}$ and $\mathrm{K}^{+}$concentrations [101]. Increased membrane tension could open stretch-activated ions chan- 
nels in astrocyte cultures [73], and astrocyte amino acids could diffuse through these channels (swelling-induced release of amino acids from astrocytes). Mechanical injury alters the volume of activated ion channels [47]. As pointed out by Levi and Gallo [82], it is possible that the establishment of a vicious circle will cause self-potentiation of the pathological process. For example, the accumulation of extracellular glutamate and $\mathrm{K}^{+}$following the traumatic and ischaemic insults could induce astrocyte swelling with further glutamate and $\mathrm{K}^{+}$efflux, and consequent potentiation of swelling and excitotoxicity.

\section{Astrocyte cell death types in severe and complicated traumatic brain injuries}

In severe brain trauma complicated by subdural or epidural haematoma we found astrocyte cells exhibiting oncotic cell death type characterized by electron lucent and swollen cytoplasm and nucleoplasm, lobulated nucleus, presence of intranuclear inclusions, apparently intact and disrupted nuclear pore complex, numerous clear vacuoles, lysosomes, and numerous small dense bodies [33] (Fig. 9A).

The presence of typical apoptotic astrocyte cell death is characterized by chromatin condensation, a disrupted perinuclear cistern and the finding of apoptotic bodies in the nucleus and cytoplasm (Fig. 9B).

Other astrocytes display coexisting oncotic and apoptotic cell death, showing chromatin condensation, empty electron lucent and disrupted cytoplasm, and swollen degenerated mitochondria. Some of these astrocytes show postmortem morphological features of necrotic cell death, characterized by disorganized nuclear chromatin, clear or dense fibrillar and granular euchromatin, clear or dense nucleoplasm,

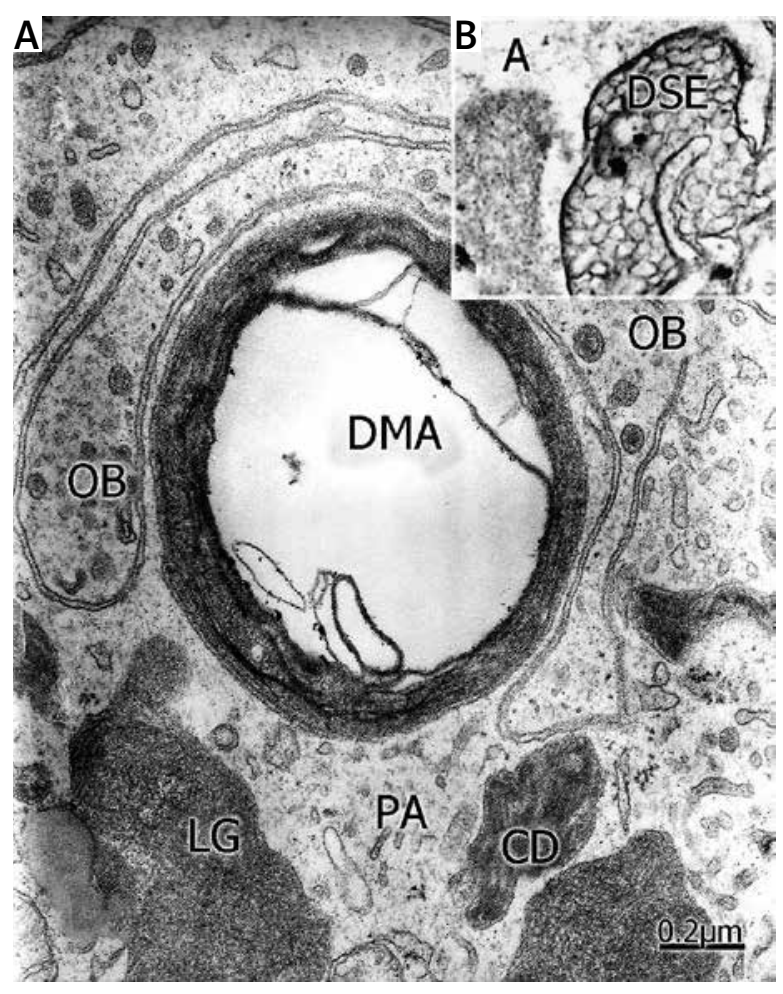

Fig. 8. A) Brain trauma. Subdural haematoma. Left parietal cortex. Phagocytic astrocyte (PA) exhibiting lamellar pseudopods containing osmiophilic bodies (OB) and vesicles, and engulfing a degenerated myelinated axon (DMA). The cytoplasm shows lipofuscin granules (LG) and remnants of nerve cell debris (CD). B) Insert showing a phagocytic astrocyte process (A) in the neuropil engulfing a degenerated presynaptic ending (DSE).

remnants of cytomembranes, small dense vesicles, massive vacuolar degeneration, plasma membrane fragmentation and degeneration, and dispersed,

Table I. Astrocyte changes in human severe traumatic brain injuries

\begin{tabular}{|lcc|}
\hline & Moderate oedema & Severe oedema \\
\hline Reactive clear swollen astrocytes & Dilated RER & Vacuolated RER \\
\hline Reactive dense swollen astrocytes & $\begin{array}{c}\text { Increased NF, Numerous L } \\
\text { Fragmented GA }\end{array}$ & Oedematous GA \\
\hline Astrocyte plasma membrane & Mostly preserved & Disrupted \\
\hline Reactive hypertrophic astrocytes & Present & Present \\
\hline Glycogen-rich and glycogen-depleted astrocytes & Present & Present \\
\hline Phagocytic astrocytes & Present & Present \\
\hline Lipofuscin-rich astrocytes & Present & Present \\
\hline Astrocyte nerve cell death types (Oncosis, Apoptosis, Necrosis) & Present & Present \\
\hline
\end{tabular}

RER - endoplasmic reticulum, M-mitochondria, GA - Golgi apparatus, NF-neurofilaments, MT-microtubules, MA - myelinated axons, L-lysosomes, $L G$ - lipofuscin granules 
degenerated mitochondria at cytoplasmic and extracellular localizations [33] (Fig. 9C).

Ischaemic neuronal death influenced by astrocytes has been described by Swanson et al. [132]. Experimental brain injury induces regional distinct apoptosis during the acute and delayed post-traumatic period [43].

A continuum of increased oncosis, apoptosis and necrosis appeared to involve astrocytes and oligodendrocytes in traumatic human brain oedema [33], and in animals following blast exposure [139]. In patients with higher brain dysfunction after mild traumatic brain injury, diagnostic imaging showed cortical neuron loss in the frontal lobes, using single-photon emission computed tomography (SPECT) with I-iomazenil, as a radioligand for the central benzodiazepine receptor [105]. Swanson and Kauppinen [132] have recently examined the influences of astrocytes on ischaemic neuronal death.

\section{The key role of aquaporin in traumatic astrocyte swelling}

Aquaporins (AQPs) play pivotal roles in cerebral water movement as essential mediators during oedema and fluid accumulation. Aquaporin 4 (AQP4), a water channel protein located at the blood-brain barrier, might facilitate the removal of this excess of water from the parenchyma into the blood. Aquaporin 4 was first located on astrocyte end-feet but later on the whole membrane of astrocytes that became hypertrophic in the most severe traumatic brain injuries [130]. The key role of aquaporin in astrocyte swelling and traumatic brain oedema has been emphasized by several investigators $[61,130,131]$. More recent studies indicate a key role of aquaporin in astrocyte swelling, ischaemia and brain oedema $[2,85,106,107,113,141]$. According to some of these studies, AQP4 expression follows an adaptive profile to the severity of traumatic brain oedema, which is probably a protective response mechanism. A very important avenue for future work in traumatic brain injuries and brain oedema is to study aquaporin as a target for pharmaceutical treatment.

\section{The dissociated astrocyte-neuronal unit in human traumatic brain injuries}

As mentioned above, normal neuronal-astrocyte cooperation is important for signalling, energy metabolism, extracellular ion homeostasis, volume regula- tion, and neuroprotection [10]. The findings described above in traumatic and complicated human brain injuries in the oedematous cerebral cortex reveal a structural alteration of the astrocyte-neuronal unit. Swollen and ischaemic neurons and swollen perineuronal astrocytes should be considered an abnormal metabolic cooperation of the astrocyte-neuronal unit. This dissociation would mean an altered astrocyte response to chemical signals from damaged neurons, which would send back other messages in the form of neuroactive and neurotrophic substances. These alterations would include not only those classical neurotransmitters and neuromodulators, but also growth factors, cytokines and prostanoids $[50,97]$.

Swollen astrocytes could be responsible for the degeneration of damaged neurons, not only for the exerted outer surface physical stress due to the notably swollen astrocyte soma, but in addition, for the establishment of high extracellular levels of glutamate released during severe traumatic brain injuries (glutamate excitotoxicity) [28,29,73-75].

These findings have led to the prevalent hypothesis that excitatory amino acid efflux is a major contributor to the development of neuronal damage subsequent to traumatic injury. Obrenovitch et al. [110] ask an interesting question related to the role of glutamate excitotoxicity in traumatic brain injuries.

\section{Hypothesis of astrocyte responsibility for production of seizures}

Astrocyte mitochondrial matrix swelling and loss of cristae [34], and early inactivation of cytochrome oxidase, have been reported after injury [41]. Since astrocyte glutamine synthesis requires ATP, it is rational to argue that in human brain trauma due to mitochondrial swelling, astrocytes would not be able to convert accumulated glutamate to glutamine. If we consider that glutamine is also a quantitatively important precursor of GABA [9], we could infer that a disturbance of the GABA-glutamine cycle and glutamate excitotoxicity could explain the seizures observed in some patients studied in our laboratory [27]. An impairment of glutamate-inactivating ability of astrocytes in human brain trauma [92] could be important in increasing the excitotoxic effect of glutamate on neurons. This hypothesis should be considered in explaining the degeneration of pyramidal and non-pyramidal nerve cells leading to nerve cell death. 

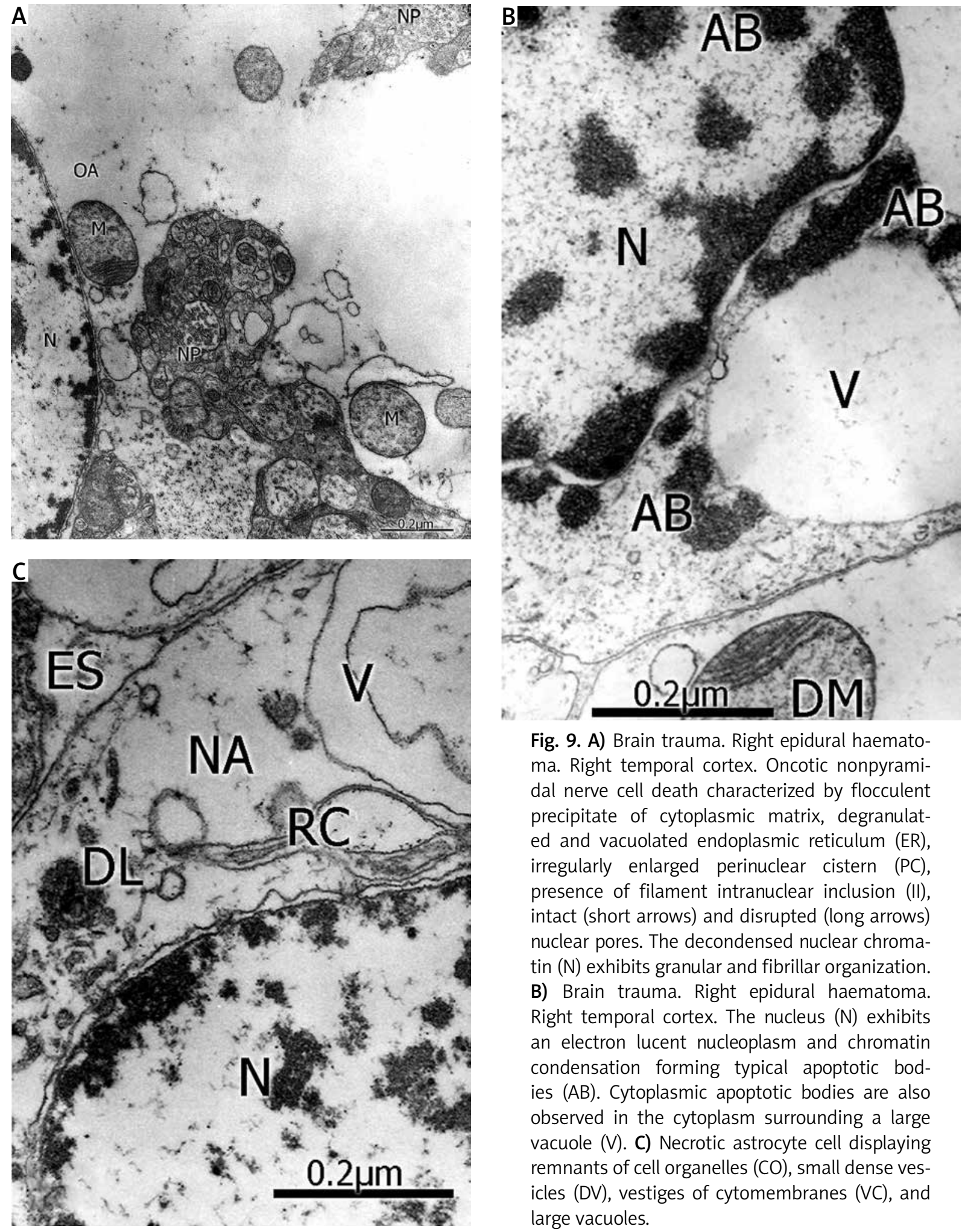

Fig. 9. A) Brain trauma. Right epidural haematoma. Right temporal cortex. Oncotic nonpyramidal nerve cell death characterized by flocculent precipitate of cytoplasmic matrix, degranulated and vacuolated endoplasmic reticulum (ER), irregularly enlarged perinuclear cistern (PC), presence of filament intranuclear inclusion (II), intact (short arrows) and disrupted (long arrows) nuclear pores. The decondensed nuclear chromatin (N) exhibits granular and fibrillar organization. B) Brain trauma. Right epidural haematoma. Right temporal cortex. The nucleus $(\mathrm{N})$ exhibits an electron lucent nucleoplasm and chromatin condensation forming typical apoptotic bodies (AB). Cytoplasmic apoptotic bodies are also observed in the cytoplasm surrounding a large vacuole (V). C) Necrotic astrocyte cell displaying remnants of cell organelles (CO), small dense vesicles (DV), vestiges of cytomembranes (VC), and large vacuoles. 
Table II. Altered astrocyte-neuronal unit

\begin{tabular}{|lcc|}
\hline & Moderate oedema & Severe oedema \\
\hline Perisynaptic astrocyte & Preserved & Absent \\
\hline Astrocytes supply substrates of glycogen metabolism & Increased & Increased \\
\hline Glio-basal dissociation process & Preserved & Dissociated \\
\hline Gap junction alteration & Present & Dissociated \\
\hline Glutamate cytotoxicity & Increased & Increased \\
\hline
\end{tabular}

Table II summarizes the abnormal astrocyte-neuronal unit in traumatic moderate and severe oedema.

\section{Concluding remarks}

Severe and complicated traumatic human brain injuries induce notably swollen astrocytes and numerous subpopulations of astrocyte subtypes, such as clear and dense oedematous astrocytes, hypertrophic reactive astrocytes, glycogen-rich and glycogen-depleted astrocytes, lipofuscin-rich astrocyte, and phagocytic astrocytes. Swollen clear and dense perineuronal astrocytes appear compressing and indenting dark, ischaemic nerve cells, degenerated myelinated axons, and synaptic contacts. At the level of the neuropil, in areas of moderate brain oedema, the perisynaptic astrocyte cytoplasmic layer appears covering axodendritic synaptic contacts, dendrites and myelinated axons. In severe oedematous regions the perisynaptic astrocytic glial ensheathment is rejected and lost by the brain oedema fluid deposited in the enlarged extracellular space. The synaptic contacts appear in direct continuity with the extracellular space impairing neurotransmission.

Glycogen-rich and glycogen-depleted perivascular astrocyte end-feet are found applied or dissociated from the capillary basement membrane. The interastrocytary gap junctions appear separated, fused and fragmented. Reactive hypertrophic astrocytes exhibit dense cytoplasmic matrix, increased amounts of dilated smooth and rough endoplasmic reticulum, microtubules, gliofilaments, and vacuolization and fragmentation of Golgi apparatus. Lipofuscin-rich astrocytes and phagocytic astrocytes are also frequently observed, induced by lipid peroxidation, and an overall spectrum of altered endosomal/lysosomal system. Some hypotheses are raised related to the absence of the perisynaptic layer, the neurobiological significance of glycogen-rich and glycogen-depleted astrocytes, the abnormal astrocyte-neuron unit, and the astrocyte responsibility for production of seizures. The results are compared with those described in experimental brain trauma, related neuropathological conditions, ischaemic processes, and in vivo and in vitro experimental conditions, in an attempt to establish a link between basic and clinical neuroscience, and to design new therapeutic strategies.

\section{Acknowledgements}

The logistic support of the Foundation for Academic Development of Zulia University is deeply appreciated. Our thanks to Lic. Orlando Castejón De Pablos and Netty Ojeda for the digital work of electron micrographs. This study has been carried out with the help of a subvention obtained from Castejón Foundation.

\section{Disclosure}

Authors report no conflict of interest.

\section{References}

1. Adams RD. Implications of the biology of the neuroglia and microglia cells for clinical neuropathology. In: Windle WF (ed.). Biology of Neuroglia. Oxford University Press, Springfield 1958; pp. 245-263.

2. Amiry-Moghaddam M, Ottersen OP. The molecular basis of water transport in the brain. Nat Rev Neurosci 2003; 4: 991-1001.

3. Anders JJ. Lactic acidification of GAP junctional communication in "in vitro" astrocytes as measured by fluorescence recovery after laser photobleaching. Glia 1988; 1: 371-379.

4. Al-Ali SY, al-Hussain SM. An ultrastructural study of the phagocytic activity of astrocytes in adult rat brain. J Anat 1996; 188: 257-262.

5. Allen IV, Kirk J, Maynard RL, Cooper GK, Scott R, Crockard A. Experimental penetrating head injury: some aspects of light microscopical and ultrastructural abnormalities. Acta Neurochir Suppl (Wien) 1983; 32: 99-104.

6. Araque A, Sanzgiri RP, Purpura V, Haydon PG. Astrocyte-induced modulation of synaptic transmission. Can J Physiol Pharmacol 1999; 77: 699-706.

7. Ballanyi K. Modulation of glial potassium, sodium and chloride activities by the extracellular milieu. In: Neuroglia. Kettenmann H, Ransom B.(eds.). Oxford University Press, New York 1995; pp. 289-298. 
8. Barron KD, Dentinger MP, Kimelberg HK, Nelson LR, Bourke RS, Keegan S, Mankes R, Kragoe EJ Jr. Ultrastructural features of a brain injury model in cat. I. Vascular and neuroglial changes and the prevention of astroglial swelling by a fluorenyl (aryloxy) alkanoic acid derivative. Acta Neuropathol 1988; 75: 295-307.

9. Bataglioni G, Martin DL. GABA synthesis in brain slices in dependent on glutamine produced in astrocytes. Neurochem Res 1991; 16: 151-156.

10. Benarroch EE. Neuron-astrocyte interactions: partnership for normal function and disease in the central nervous system. Mayo Clin Proc 2005; 80: 1326-1338.

11. Bignami A, Ralston HJ. The cellular reaction to Wallerian degeneration in the central nervous system of the cat. Brain Res 1969; 13: 444-461.

12. Bignami A, Dahl D. In: Gliosis. Neuroglia. Kettenmann H, Ransen B (eds.). Oxford University Press, New York 1995; pp. 843-858.

13. Boehme DH, Leonberg SC, Varagiannis E, Marks N. On the neurochemistry of an adult form of ceroid lipofuscinosis (Kuf's disease). Prog Clin Biol Res 1980; 39: 305-314.

14. Boldrini R, Biselli R, Santorelli FM, Bosman C. Neuronal ceroid lipofuscinosis: an ultrastructural, genetic, and clinical study report. Ultrastruct Pathol 2001; 25: 51-58.

15. Bullock R, Maxwell WL, Graham DI, Teasdale GM, Adams JH. Glial swelling following human cerebral contusion: an ultrastructural study. J Neurosurg Psychiatr 1991; 54: 427-434.

16. Burkovetskaya M, Karpuk N, Xiong J, Bosch M, Boska MD, Takeuchi H, Suzumura A, Kielian T. Evidence for aberrant astrocyte hemichannel activity in Juvenile Neuronal Ceroid Lipofuscinosis (JNCL). PLoS One 2014; 9: e95023.

17. Butt AM, Kirvell S. Glial cells in transected optic nerves of immature rats. II. An immunohistochemical study. J Neurocytol 1996; 25: 381-392.

18. Calvo JL, Carbonell AL, Boya J. Coexpression of glial fibrillary acidic protein and vimentin in reactive astrocyte following brain injury in rats. Brain Res 1991; 566: 333-336.

19. Cammermayer J. Astroglial changes during retrograde atrophy of the nucleus facials in mice. J Comp Neurol 1955; 102: 133-150.

20. Canady KS, Hyson RL, Rubel EW. The astrocytic response to afferent activity blockade in chick nucleus magnocellularis is independent of synaptic activation, age, and neuronal survival. J Neurosci 1994; 14: 5973-5985.

21. Cancilla PA, Breedy J, Berliner J, Sharifi-Nia H, Toga AW, Santony EM, Scully S, Devellis J. Expression of MRNA for glial fibrillary acidic protein after experimental brain injury. J Neuropathol Exp Neurol 1992; 51: 560-565.

22. Castejón OJ. Electron microscopic study of capillary wall in human cerebral edema. J Neuropathol Exp Neurol 1980; 39: 296 328.

23. Castejón OJ. Electron microscopic study of central axonal degeneration in traumatic human brain edema. J Submicrosc Cytol 1985; 17: 703-718.

24. Castejón OJ, Valero C, Díaz, M. Light and electron microscope study of nerve cells in traumatic edematous human cerebral cortex. Brain Injury 1997; 11: 363-388.

25. Castejón OJ. Ultrastructural alterations of human cortical capillary basement membrane in perifocal brain edema. J Submicrosc Cytol Pathol 1988; 20: 519-536.
26. Castejón OJ. Morphological astrocytic changes in complicated human brain trauma. A light and electron microscopic study. Brain Injury 1998; 12: 409-427.

27. Castejón OJ. Electron microscopic analysis of cortical biopsies in patients with traumatic brain injuries and dysfunction of neurobehavioural system. J Submicrosc Cytol Pathol 1998; 30: 145-156.

28. Castejón OJ. Astrocyte subtypes in the gray matter of injured human cerebral cortex. A transmission electron microscopic study. Brain Injury 1999; 13: 291-304.

29. Castejón OJ, Castejón HV, Diaz M, Castellano A. Consecutive light microscopy, scanning-transmission electron microscopy and transmission electron microscopy of traumatic human brain oedema and ischaemic brain damage. Histol Histopathol 2001; 16: 1117-1134.

30. Castejón OJ, Díaz M, Castejón HV, Castellano A. Glycogen-rich and glycogen-depleted astrocytes in the oedematous human cerebral cortex associated with brain trauma, tumours and congenital malformations: an electron microscopy study. Brain Injury 2002; 116: 109-132.

31. Castejón OJ, Castejón HV, Díaz M, Sánchez M, Zavala M. A light and electron microscoy study of edematous human cerebral cortex in two patients with post-traumatic seizures. Brain Injury 2002; 16: 331-346.

32. Castejón OJ. Lysosome abnormalities and lipofucsin content of nerve cells of edematous cerebral cortex. I Submicrosc Cytol Pathol 2004; 36: 263-271.

33. Castejón OJ, Arismendi G. Nerve cell death types in the edematous human cerebral cortex. J Submicrosc Cytol Pathol 2006; 38: 21-36.

34. Castejón OJ. Structural pattern of injured mitochondria in oedematous human cerebellar cortex. Brain Injury 2004; 18: 1107-1126.

35. Castejón OJ. Ultrastructural pathology of endothelial tight junctions in human brain oedema. Folia Neuropathol 2012; 50: 118-129.

36. Castejón OJ. Increased vesicular and vacuolar transendothelial transport in traumatic human brain oedema. A review. Folia Neuropathol 2013; 51: 93-102.

37. Castejón OJ. Ultrastructural alterations of human cortical capillary basement membrane in perifocal brain edema. Folia Neuropathol 2014; 52: 1-9.

38. Cervós-Navarro J. Brain edema due to ionizing radiation. In: Brain Edema. Klatzo Y, Seitelberger F (eds.). Springer-Verlag, New York 1967; pp. 632-638.

39. Chen H, Sun D. The role of Na-K-Cl co-transporter in cerebral ischemia. Neurol Res 2005; 27: 280-286.

40. Chen S, Pickard JD, Harris NG. Time course of cellular pathology after controlled cortical impact injury. Exp Neurol 2003; 182: 87-102.

41. Clendenon NR, Allen N. Organelle and membrane defects: Lysosomes, mitochondria and cell membranes. In: Neural Trauma. Seminars in Neurological Surgery. Popp A, Bowoke RS, Nelson LR, Kimelberg HK (eds.). Raven Press, New York 1979; pp. 115-129.

42. Coles JA. Glial cells and the supplement of substrates of energy metabolism to neurons. In: Neuroglia. Kettenmann H, Ranson H (eds.). Oxford University Press, New York 1995; pp. 793-804. 
43. Conti AC, Raghupathi R, Trojanowski JQ, Mcintosh TK. Experi mental brain injury induces regionally distinct apoptosisdur ing the acute and delayed post-traumatic period. J Neurosci 1998; 18: 5663-5672.

44. Del Bigio MR, Deck JH, Davidson GS. Glial swelling with eosinophilia in human post-mortem brains: a change indicative of plasma extravasation. Acta Neuropathol 2000; 100: 688-694.

45. Derugin N, Wendland M, Muramatsu K, Roberts TP, Gregory G, Ferreiro DM, Vexler ZS. Evolution of brain injury after transient middle cerebral artery occlusion in neonatal rats. Stroke 2000; 31: 1752-1761.

46. Dermietzel R. Gap junction wiring: a 'new' principle in cell-tocell communication in the nervous system? Brain Res Brain Res Rev 1998; 26: 176-183.

47. Di X, Goforth PB, Bullock R, Ellis E, Satin L. Mechanical injury alters volume of activated ion channels in cortical astrocytes. Acta Neurochir (Suppl) 2000; 76: 379-383

48. Dietrich WD, Alonso O, Halley M, Busto R. Delayed posttraumatic brain hyperthermia worsens outcome after fluid percussion brain injury: a light and electron microscopic study in rats. Neurosurgery 1996; 38: 533-541.

49. Drochman P. Morphologie du glycogène. Étude au micros copie électronique de colorations négatives du glycogènes. J Ultrastruct Res 1962; 6: 141-163.

50. Eddleston M, Mucke L. Molecular profile of reactive astrocytes implications for their role in neurologic disease. Neuroscience 1993; 54: 15-36.

51. Eng LF, Shiurba RA. Glial fibrillary acidic protein: a review of structure, function, and clinical application. In: Neuronal and Glial Proteins: Structure, Function and Clinical Application. Vol. 2. Marangos PJ, Campbell I, Cohen RM (eds.). Academic Press, New York 1988; pp. 339-359.

52. Eng LF. Glial fibrillary acidic protein: the major protein of glial intermediate filaments in differentiated astrocytes. J Neuroimmunol 1985; 8: 203-205.

53. Eng LF. Astrocyte response to injury. In: Current Issues in Neural Regeneration Research. Reir PJ, Bunge J, Seil J (eds.). Alan R Liss, New York 1988; pp. 220-230.

54. Farooque M, Badonic T, Olsson Y, Holtz A. Astrocytic reaction after graded spinal cord compression in rats: immunohistochemical studies on glial fibrillary acidic protein and vimentin. J Neurotrauma 1995; 12: 41-52.

55. Fotheringham AP, Davies CA, Davies I. Oedema and glial cell involvement in the aged mouse brain after permanent focal ischaemia. Neuropathol Appl Neurobiol 2000; 26: 412-423.

56. Fujisawa H, Maxwell WL, Graham DI, Reasdale GM, Bullock R. Focal microvascular occlusion after acute subdural haematoma in the rat: a mechanism for ischaemic damage and brain swelling? Acta Neurochir (Suppl) 1994; 60: 193-196.

57. Gallyas F, Horváth Z, Dávid K, Liposits Z. An immediate morphopathologic response of a subpopulation of astrocytes to electroshock: "dark" astrocytes. Neurobiology 1994; 2: 245-253.

58. García JH, Lossinsky AS, Nishimoto K, Klatzo Y, Lightfoote Jr. W. Cerebral microvasculature in ischemia. In: Advances in Neurology. Cervós-Navarro J (ed.). Raven Press, New York 1978; pp. 141-148.

59. Gilmore SA, Sims TJ, Leiting JE. Astrocyte reactions in spina gray matter following sciatic axotomy. Glia 1990; 3: 342-349.
60. Graeber MB, Kreutzberg W. Delayed astrocyte reaction following facial nerve axotomy. J Neurocytol 1988; 17: 209-220.

61. Ghabriel MN, Thomas A, Vink R. Magnesium restores altered aquaporin-4 immunoreativity following traumatic brain injury to a pre-injury state. Acta Neurochir (Suppl) 2006; 96: 402-406.

62. Gonatas NK, Martin J, Evangelista I. The osmiophilic particles of astrocytes. Viruses, lipid droplets or products of secretion? J Neuropathol Exp Neurol 1967; 26: 369-376.

63. Harsan LA, Poulet P, Guignard B, Parizel N, Skoff RP, Ghandour MS. Astrocyte hypertrophy in dysmielination influences the diffusion anisotropy of white matter. J Neurosci Res 2007; 85: 935-944.

64. Haymaker W, Miguel J, Ibrahim MZM. Glycogen accumulation following brain trauma. Top Probl Psychiatr Neurol 1970; 10: 71-87.

65. Höke A, Silver J. Heterogeneity of astrocytes in reactive gliosis. Perspect Dev Neurobiol 1994; 2: 269-274.

66. Hossain MZ, Peeling J, Sutherland R, Hertzberg EL, Nagy Jl. Ischemia-induced cellular redistribution of the astrocytic gap junctional protein connexin43 in rat brain. Brain Res 1994; 652: 311-322

67. Ito U, Kuroiwa T, Hanyu S, Hakamata Y, Kawakami E, Nakano I, Oyanigi K. Temporal profile of experimental ischemic edema after threshold amount of insult to induce infarction, ultrastructure, gravimetry and Evans' blue extravasation. Acta Neurochir (Suppl) 2003; 86: 131-135.

68. Janeczko K. The proliferative response of astrocytes to injure in neonatal brain: A combined immunocytochemical and autorradiographic study. Brain Res 1988; 456: 280-285.

69. Kamyrio T, López MB, Kassell NF, Steiner L, Lee KS. Radiosurgery-induced microvascular alterations precede necrosis of the brain neuropil. Neurosurgery 2001; 49: 409-414.

70. Kaur C, Slingh J, Lim MK, Ng BL, Yap EP, Ling EA. Ultrastructural changes of macroglial cells in the rat brain following an exposure to a non-penetrative blast. Ann Acad Med (Singapore) 1997; 26: 27-29.

71. Kiehn O, Tresch MC. Gap junctions and motor behaviour. Trends Neurosci 2002; 25: 108-115.

72. Khurgel M, Ivy GO. Astrocytes in kindling: relevance to epileptogenesis. Epilepsy Res 1996; 26: 163-175.

73. Kimelberg HK, Goderic SK, Higman S, Pang S, Warriewski RA. Swelling-induced release of glutamate, aspartate, and taurine from astrocyte cultures. J Neurosci 1990; 10: 1583-1591.

74. Kimelberg HK. Astrocytic edema in CNS trauma. J Neurotrauma (Suppl) 1992; 1: S71-S81.

75. Kimelberg HK. Brain Edema. In: Neuroglia. Kettenmann H, Ramson BR (eds.). Oxford University Press, New York 1995; pp. 919-935.

76. Klatzo I. Neuropathological aspect of brain edema. J Neuropathol Exper Neurol 1967; 26: 1-14.

77. Kost-Micucki SA, Oblinger MM. Changes in glial fibrillary acidic protein mRNA expression after corticospinal axotomy in the adult hamster. J Neurosci Res 1991; 28: 182-188.

78. Krsulovic J, Couve E, Roncagiolo M. Dysmyelination, demyelination and reactive astrogliosis in the optic nerve of the taiep rat. Biol Res 1999; 32: 253-262.

79. Kuchiwaki H, Takada S, Itoh J, Nagasaka M, Kageyama N. Distribution andconstitutional changes of edema fluid in cyto- 
toxic brain edema analyzed by electron microscopy and differential scanning calorimetry. No To Shinkei 1987; 39: 463-470.

80. Kuroiwa T, Nagaoka T, Ueki M, Yamada I, Miyasaka N, Akimoto $\mathrm{H}$. Different apparent diffusion coefficient: water content correlations of gray and white matter during early ischemia. Stroke 1998; 29: 859-865.

81. Latov N, Nilavev G, Zimmerman EA, Johnson WG, Silverman AJ, Defendim R, Cote L. Fibrillary astrocytes proliferate in response to brain injury: A study combining immunoperoxidase technique for glial fibrillary acidic protein and radioautography of tritiated thymidine. Dev Biol 1979; 72: 381-384.

82. Levi G, Gallo V. Release of neuroactive aminoacids from glia. In: Neuroglia. Kettenman H, Ransom BR (eds.). Oxford University Press, New York 1995; pp. 815-826.

83. Lehmann GL, Gradilone SA, Marinelli RA. Aquaporin water channels in central nervous system. Curr Neurovasc Res 2004 1: 293-303.

84. Li WE, Ochalski PA, Hertzberg EL, Nagy JI. Immunorecognition, ultrastructure and phosphylation status of astrocytic gap junctions and connexin43 in rat brain after cerebral focal ischaemia. Eur J Neurosci 1998; 10: 2444-2463.

85. Lo AC, Chen AY, Hung VK, Yaw LP, Fung MK, Ho MC, Tsang MC, Chung SS, Chung SK. Endothelin-1 overexpression leads to further water accumulation and brain edema after middle cerebral artery occlusion via aquaporin 4 expression in astrocytic end-feet. J Cerebr Blood Flow Metab 2005; 25: 998-1011.

86. Long DM, Hartman JF, French L. The ultrastructure of human cerebral edema. J Neuropathol Exp Neurol 1966; 25: 373-395.

87. Ludowyk PA, Hughes W, Hugh A, Willenborg DO, Rockett K, Parish CR. Astrocytic hypetrophy: an import pathological feature of chronic experimental autoimmune encephalitis in aged rats. J Neuroimmunol 1993; 48: 121-134.

88. Maeda M, Akai F, Yanagihara T. Neuronal integrity and astrocytic reaction in cold injury: an immunohistochemical investigation. Acta Neuropathol 1997; 94: 116-123.

89. Magistreti PJ, Hoff PR, Martin JL. Adenosine stimulates glycogenolisis in mouse cerebral cortex: A possible coupling mechanism between neuronal activity and energy metabolism. J Neurosci 1986; 6: 2558-2562.

90. Makowski L, Caspar DLD, Phillips WC, Goodenough DA. Gap junction structures. J Cell Biol 1974; 74: 629-645.

91. Malhotra SK, Shnitka TK, Elbrink J. Reactive astrocytes: A review. Cytobios 1990; 61: 133-160.

92. Martin D. The role of glia in the inactivation of neurotransmitter. In: Neuroglia. Kettenmann H, Ransom BR (eds.). Oxford University Press, New York 1995; pp. 732-745.

93. Mázló M, Gasz B, Szigeti A, Zsombok A, Gallyas F. Debris of "dark" (compacted) neurons are removed from an otherwise undamaged environment mainly by astrocytes via blood ves sels. J Neurocytol 2004; 33: 557-567.

94. Mathew P, Bullock R, Graham DI, Maxwell WL, Teasdale GM, Mc Cullock J. A new experimental model of contusion in the rat. Histopathological analysis and temporal patterns of cerebral blood flow disturbance. J Neurosurg 1996; 85: 860-870.

95. Mathewson AJ, Berry. Observations on the astrocyte response to a cerebral stab wound in adult rat. Brain Res 1985; 327: 61-69.
96. Matyja E, Taraszewska A, Naganska E, Rafalowska J, Gebarowska J. Astroglial alterations in amyotrophic lateral sclerosis (ALS) model of slow glutamate excitotoxicity in vitro. Folia Neuropathol 2006; 44: 183-190.

97. Merryl JE. Lymphokines, morokines and glial cells. In: Volume Transmission in the Brain: Novel Mechanism for Neural Transmission. Fuxe K, Agnati LF (eds.). Raven Press, New York 1991; pp. 267-277.

98. Miyake T, Hallory T, Fukuda M, Kitamura T, Fujita S. Quantitative studies on proliferative changes of reactive astrocytes in mouse cerebral cortex. Brain Res 1988; 451: 133-138.

99. Miyake T, Okada M, Kitamura T. Reactive proliferation of astrocytes studied by immunohistochemistry for proliferating cell nuclear antigen. Brain Res 1992; 590: 300-302.

100. Monteiro RAF, Rocha E, Marini-Abreu MO. Age-related morphometric changes occurring in the somata of astrocytes of the granular layer of rat neocerebellar cortex (Crus I and Crus II). Histol Histopathol 1992; 7: 427-444.

101. Mori K, Miyazaki M, Iwase H, Maeda M. Temporal profile of change in brain tissue extracellular space and extracellular ion ( $\mathrm{Na}(+), \mathrm{K}(+))$ concentrations after cerebral ischemia and the effects in mild cerebral hypothermia. J Neurotrauma 2002; 19: $1261-1270$

102. Moumdjian RA, Antel JP, Yong VW. Origin of contralateral reactive gliosis in surgically injured rat cerebral cortex. Brain Res 1991; 547: 223-228.

103. Murray M, Wang SD, Goldberger ME, Levitt P. Modification of astrocytes in the spinal cord following dorsal root or peripheral nerve lesions. Exp Neurol 1990; 110: 248-257.

104. Nagy JI, Ochalski PA, Li J, Hertzberg EL. Evidence for the co-localization of another connexin with connexin-43 at astrocytic gapjunctions in rat brain. Neuroscience 1997; 78: 533-548.

105. Nakagawara J, Kamiyama K, Takahashi M, Nakamura H. Cortical neuron loss in post-traumatic higher brain dysfunction using (123)I-iomazenil SPECT. Acta Neurochir (Suppl) 2013; 118: $245-250$

106. Nicchia GP, Frigeri A, Liuzzi GM, Svelto M. Inhibition of aquaporin-4 expression in astrocytes by RNAi determines alteration in cell morphology, growth, and water transport and induces changes in ischemia-related genes. FASEB J 2003; 17: 1508-1510.

107. Nicchia GP, Nico B, Camassa LM, Mola MG, Loh N, Dermietzel R, Spray DC, Svelto M, Frigeri A. The role of aquaporin-4 in the blood-brain barrier development and integrity: studies in animal and cell culture models. Neuroscience 2004; 129: 935-945.

108. Nillson P, Hillered L, Olson L, Sheardown MJ, Hansen AJ. Regional changes in interstitial $\mathrm{K}+$ and $\mathrm{Ca} 2+$ levels following cortical compression trauma in rats. Cerebr Blood Flow Metab 1963; 13: 183-192.

109. Oblinger MM, Singh LD. Reactive astrocytes in neonate brain upregulate intermediate filament gene expression in response to axonal injury. Int I Dev Neurosci 1993; 11: 149-156.

110. Obrenovitch TP, Urenjak J. Is high extracellular glutamate the key to excitotoxicity in traumatic brain injury? I Neurotrauma 1997; 14: 677-698.

111. Oswald MJ, Palmer DN, Kay GW, Shemilt SJ, Rezaie P, Cooper JD. Glial activation spreads from specific cerebral foci and pre- 
cedes neurodegeneration in presymptomatic ovine neuronal ceroid lipofuscinosis (CLN6). Neurobiol Dis 2005; 20: 49-63.

112. Palmer DN, Oswald MJ, Westlake VJ, Kay GW. The origin of fluorescence in the neuronal ceroid lipofuscinoses (Batten disease) and neuron cultures from affected sheep for studies of neurodegeneration. Arch Gerontol Geriatr 2002; 34: 343-357.

113. Papadopoulos MC, Manley GT, Krishna S, Verkman AS. Aquaporin-4 facilitates reabsorption of excess fluid in vasogenic brain edema. FASEB J 2004; 18: 1291-1293.

114. Persson LI, Rosengren LE, Hansson HA. Ultrastructural studies on blood-brain barrier dysfunction around cerebral stab wounds, aggravated by acute ethanol intoxication. Acta Neurol Scandinav 1978; 57: 405-417.

115. Plesnila N, Ringel F, Chang RC, Staub F, Baethmann A. Relevance of calcium homeostasis in glial cell swelling from acidosis. Acta Neurochir (Suppl) 1998; 71: 203-205.

116. Porter JT, Mc Carthy KD. Astrocyte neurotransmitter receptors in in situ and in vivo. Progr Neurobiol 1997; 51: 439-455.

117. Povlishock JT, Becker DP, Sullivan HG, Miller JD. Vascular permeability alterations to horseradish peroxidase in experimental brain injury. Brain Res 1978; 153: 223-239.

118. Povlishock JT. The morphopathological responses in head injuries of varying severity. Central Nervous System Trauma: Status Report. In: Becker DP, Povlishock JT (eds.). NINCDS, Washington 1985; pp. 443-455.

119. Raivich G, Bohatschek M, Kloss CU, Werner A, Jones LL, Kreutzberg GW. Neuroglial activation repertoire in the injured brain graded response, molecular mechanisms and cues to physiological function. Brain Res Rev 2002; 30: 77-105.

120. Ragaisis V. Brain contusion: morphology pathogenesis and treatment. Medicina (Kaunas) 2002; 38: 243-249.

121. Ranson B. Gap junctions. Neuroglia. In: Kettenmann H, Ranson BR (eds.). Oxford University Press, New York 1995; pp. 299-318.

122. Rash JE, Duffy HS, Dudek FE, Bilhartz BL, Whalen LR, Yasumura T. Grid-mapped freeze-fracture analysis of gap junctions in gray and white matter of adult rat central nervous system, with evidence for a "panglial syncytium" that is not coupled to neurons. J Comp Neurol 1997; 388: 265-292.

123. Reier PJ. Gliosis following CNS injury: The anatomy of astrocyte scars and their influences on axonal elongation. Astrocytes. Vol. 3. In: Fedoroff S, Vernakadi A (eds.). Academic Press, New York 1986; pp. 263-324.

124. Rio Hortega PD, Penfield W. Cerebral cicatrix: the reaction of neuroglia and microglia to brain wounds. Johns Hopkins Hosp Bull 1927; 41: 278-303.

125. Roesmann V, Gambetti P. Pathological reaction of astrocytes in perinatal brain injury: immunohistochemical study. Acta Neuropathol (Berl) 1986; 70: 302-307.

126. Salahuddin TC, Johansson BB, Kalimo H, Olsson Y. Structural changes in the rat brain after carotid infusions of hyperosmolar solutions. An electron microscopic study. Acta Neuropatho 1988; 77: 5-13.

127. Sasaki S, Ferzt R, Cervós Navarro J. Transendothelial vesicular transport of protein in brain edema induced by ultraviolet irradiation. Acta Neuropathol 1977; 40: 207-212.

128. Schousboe A. Transport and metabolism of glutamate and GABA in neurons and glial cells. Int Rev Neurobiol 1981; 22: 1-45.
129. Sims TJ, Gilmore SA. Glial response to dorsal root lesion in the irradiated spinal cord. Glia 1992; 6: 96-107.

130. Sobue K, Asai K, Katsuya H. Aquaporin water channels in the brain and molecular mechanism of brain edema. Nippon Rinsho 2006; 64: 1181-1189.

131. Suzuki R, Okuda M, Asai J, Nagashima G, Itokawa H, Matsunaga A, Fujimoto T, Suzuki T. Astrocytes co-express aquaporin-1, -4 , and vascular endothelial growth factor in brain edema tissue associated with brain contusion. Acta Neurochirurg (Suppl) 2006; 96: 398-401.

132. Swanson RA, Ing W, Kauppinen TM. Astrocyte influences on ischemic neuronal death. Curr Mol Med 2004; 4: 193-205.

133. Theriault E, Frankenstein UN, Hertzberg EL, Nagy JI. Connexin43 and astrocytic gap junctions in the rat spinal cord after acute compression injury. I Comp Neurol 1997; 382: 199-214.

134. Thiel HJ, Hammersen F, Sauer R. Histochemical and ultrastructural studies on the anti-edema and radiation-protective effects of 0-(beta-hydroxyethyl)-rutosides in the rat brain after single-dose irradiation. 1. Electron microscopy study of terminal blood circulation. Strahlenther Onkol 1988; 164: 544-552.

135. Tomas-Camardiel M, Venero JL, Herrera AJ, De Deblos RM, Pintor-Toro JA, Machado A, Cano J. Blood-brain barrier disruption highly induces aquaporin-4 mRNA and protein in perivascular and parenchymal astrocytes: protective effect by estradiol treatment in ovariectomized animals. J Neurosci Res 2005; 80: $235-246$

136. Tóth Z, Séress L, Tóth P, Ribak CE, Gallyas F. A common morphological response of astrocytes to various injuries: "dark" astrocytes. A light and electron microscopic analysis. J Hirnforsch 1997; 38: 173-186.

137. Uranova NA. Brain synaptic plasticity in schizophrenia. Vestn Ross Akad Med Nauk 1996; 4: 23-29.

138. Vajtr D, Benada O, Kukacka J, Průsa R, Houstava L, Toupalík P, Kizek R. Correlation of ultrastructural changes of endothelial cells and astrocytes occurring during blood brain barrier damage after traumatic brain injury with biochemical markers of BBB leakage and inflammatory response. Physiol Res 2009; 58: 263-268

139. Vise WN, Liss L, Yashow D, Hunt WE. Astrocytic process: A route between vessels and neurons following brain barrier injury. J Neuropathol Exp Neurol 1975; 34: 324-334.

140. Yarnell AM, Shaughness MC, Barry ES, Ahlers ST, McCarron RM, Grunberg NE. Blast traumatic brain injury in the rat using a blast overpressure model. Curr Protoc Neurosci 2013; 9: 9-41.

141. Zhao J, Moore AN, Clifton GL, Dash PK. Sulforaphane enhances aquaporin-4 expression and decreases cerebral edema following traumatic brain injury. J Neurons Res 2005; 82: 499-506. 